\title{
Resultados monetarios de la sustentabilidad presentados en cuatro cuentas de resultados: una propuesta para las pymes en México*
}

[Artículos]

\author{
María Antonieta Monserrat Vera Muñoz** \\ Rafaela Martínez Méndez ${ }^{* * *}$ \\ José Gerardo Serafín Vera Muñoz ${ }^{* * *}$
}

Recibido: 05 de abril de 2021

Aprobado: 15 de junio de 2021

Citar como:

Monserrat-Vera, M. A., Martínez, R. y Serafín-Vera, J.G., (2021). Resultados monetarios de la Sustentabilidad presentados en cuatro cuentas de resultados: Una propuesta para las pymes en México. Revista Activos, 19(1). https://doi.org/10.15332/25005278.6688

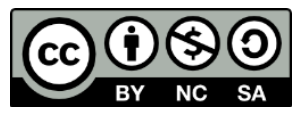

\footnotetext{
* El artículo deriva de la elaboración del libro Responsabilidad social empresarial: prácticas de desarrollo sustentable y la contabilidad ecológica, publicado en 2017.

** Dra. En Dirección de Organizaciones. Profesor investigador de tiempo completo

** Dra. En Dirección de Organizaciones. Profesor investigador de tiempo completo en la Facultad de Contaduría de la BUAP. Correo electrónico: monserrat.vera@correo.buap.mx; ORCID: https://orcid.org/0000-0003-1940-5326

${ }^{* * *}$ Dra. En Ciencias de la Administración. Profesor investigador de tiempo completo en la Facultad de Contaduría de la BUAP. Correo electrónico: rafaela.martinez@correo.buap.mx; ORCID: https://orcid.org/0000-0002-1878-1891

${ }^{* * * *}$ Dr. En Ciencias de la Administración. Profesor investigador de tiempo completo en la Facultad de Contaduría de la BUAP. Correo electrónico: gerardo.vera@correo.buap.mx; ORCID:

https://orcid.org/0000-0002-9934-6276
}

\section{Revista Activos}

ISSN: 0124-5805 | e-ISSN: 2500-5278 | DOI: https://doi.org/10.15332/25005278

Vol. 19 N.o 1 | enero-junio de 2021 


\section{Resumen}

El eminente deterioro del planeta marca el reto para los seres humanos contribuyan a minimizarlo. Una forma de apoyar por parte de algunos contadores públicos es involucrarse con las necesidades de registros monetarios, relacionados con aspectos sociales y ambientales para evidenciar la actividad de las empresas a favor de la sustentabilidad. El propósito de este trabajo es indagar respecto a la contabilidad sustentable y la forma en que las pequeñas y medianas empresas (pymes) mexicanas puedan presentar los resultados monetarios de acciones sustentables, con la propuesta del uso de cuatro cuentas de resultados (CCR), partiendo del análisis y comparación de la matriz de triple cuenta de resultados (Triple Bottom Line [TBL]) de Elkington (1998). Mediante un estudio descriptivo y exploratorio, se obtuvieron resultados que muestran el beneficio para las pymes al exhibir su quehacer a favor de la sustentabilidad, con la propuesta de la matriz CCR.

Palabras clave: sustentabilidad, contabilidad sustentable, matriz triple cuenta de resultados, pymes.

Clasificación JEL: Q56, M49.

\section{Monetary results of sustainability presented in four income statements: a proposal for SMEs in Mexico}

\section{Abstract}

The eminent deterioration of the planet sets the challenge for human beings to contribute to minimize it. One way to contribute by some public accountants is to engage with the needs of monetary records, related to social and environmental aspects to demonstrate the activity of companies in favor of sustainability. So the purpose of this paper is to investigate about sustainable accounting and how Mexican small and medium-sized enterprises (SMEs) can present the monetary results of sustainable actions, with the proposed use of four income statements 
(CCR, in Spanish), based on the analysis and comparison of Elkington's

Triple Bottom Line (TBL) matrix (1998). With a descriptive and

exploratory study, results were obtained that show the benefit for SMEs when displaying their work in favor of sustainability, with the proposal of the CCR matrix.

Keywords: sustainability, sustainable accounting, triple bottom line matrix, SMEs.

JEL classification: Q56, M49.

\section{Introducción}

Según el Instituto Nacional de Ecología y Cambio Climático (INECC, 2018), en 1990, las emisiones de GEI en México fueron 445 MtCO2e, y entre 1990 y el 2015 las emisiones de México aumentaron un 54 \%. El gas más relevante que emite México es el bióxido de carbono con $71 \%$ de las emisiones, seguido del metano con $21 \%$. Estas cifras muestran altos índices de contaminación, lo que la convierte en un reto para las empresas que les exige participar con acciones a favor de la sustentabilidad. Para los profesionales de Contaduría esto también es un desafío, pues deben complementar la información que presentan tradicionalmente y al mismo tiempo traducirla en oportunidades, como las de precisar y resguardar los actos y actividades de los compromisos de las empresas hacia el medio ambiente y la mejora social.

En este orden de ideas, algunos contadores se han motivado a realizar investigaciones sobre el tema y han presentado algunas alternativas como la creación de un instrumento para la evaluación de la sustentabilidad y la responsabilidad social en las pymes con 5 dimensiones como el trabajo de García de la Torre et al. (2019), entre otros. Sin embargo, aún está pendiente validar una propuesta de indicadores generalmente aceptados para medir cuantitativa y cualitativamente las dimensiones que integran la 
sustentabilidad y así poder reflejarlos en términos monetarios en los estados financieros, prácticas relacionadas con la sustentabilidad, en particular lo que hacen las empresas para contribuir a esta. Siguiendo con la contribución de la empresa a la sustentabilidad el contador ya ha comenzar con algunas propuestas, como recomendar el uso de tecnologías limpias y cuantificar los beneficios económicos adicionales al medioambiente y a la sociedad que tendrían las pymes con su uso.

Un punto de inicio en el presente trabajo es tener información y dar a conocer qué es la contabilidad sustentable y, con ello, tener la posibilidad de contribuir con una propuesta para la presentación de información de sustentabilidad para las pymes. Con la finalidad de pasar de pyme a pyme sustentable, la propuesta que se aporta en el presente escrito se apoya en la matriz de la triple cuenta de resultados (Triple Bottom Line [TBL]) de Elkington (1998), trabajo que se toma como referencia juntamente con la G4 Guía para elaboración de memorias de sostenibilidad emitida por Global Reporting Initiative (GRI, 2013). Con base en su análisis, se identifica la exhibición de resultados económicos, sociales y medioambientales, lo que da la oportunidad de proponer agregar una cuarta cuenta en la que se contempla la cultura; desde una apreciación empírica esta influye de forma importante en los contextos donde se ubican las empresas. Por esto, se considera una matriz con cuatro cuentas de resultados.

El trabajo presenta una revisión de la literatura relacionada con 9 subtemas: 1) sustentabilidad; 2) contabilidad; 3) contabilidad sustentable; 4) elaboración de informes de sustentabilidad; 5) la Global Reporting Initiative (GRI); 6) la matriz de triple cuenta de resultados; 7) normas y pronunciamientos contables; 8) empresas que elaboran reportes de sustentabilidad, y 9) pymes. Posteriormente se incluye la metodología, seguida de los resultados, que se integran por el comparativo de 
indicadores y la propuesta, que se complementa con la discusión.

Finalmente se presentan las conclusiones, referencias y los anexos.

\section{Revisión de la literatura}

\section{Sustentabilidad}

En el Informe Brundtland, resultado de la asamblea realizada por la Organización de Naciones las Unidas (ONU) en 1987, se definió la sustentabilidad como la capacidad de satisfacer necesidades de la generación humana actual sin menoscabo de que las generaciones futuras puedan satisfacer las necesidades propias.

En el transcurrir del tiempo, se han manejado términos ligados a la sustentabilidad como desarrollo sustentable, que se aboca a la preservación de los recursos naturales, y el desarrollo sostenible, que considera recursos naturales sumados a las condiciones sociales, políticas y económicas. La sustentabilidad se relaciona con e involucra a todo tipo de empresas, independientemente de su giro y tamaño, por lo que las pymes también están incluidas. Es prudente marcar la diferencia entre los términos sustentable y sostenible, que en variadas ocasiones se han utilizado como sinónimos. Si bien el primero ya fue abordado con antelación, el termino sostenible se aboca en un sentido amplio para defender lo sustentable1. En este trabajo, se utiliza el término 'sustentable' con el propósito de evidenciar, en términos monetarios, las prácticas empresariales ejecutadas que tengan relación con las dimensiones de la sustentabilidad.

\footnotetext{
1 "Lo sustentable se aplica a la argumentación para explicar razones o defender, en tanto que lo sostenible es lo que se puede mantener durante largo tiempo sin agotar los recursos" (Secretaría de Medio Ambiente y Recursos Naturales de México, 2018).
} 
La Unión Europea (UE) propone seis acciones para el desarrollo sostenible (sustentabilidad):

1. Integración de los aspectos medioambientales en los otros ámbitos de actividad.

1. Cooperación compartida de la responsabilidad entre la UE, los Estados miembros, el mundo empresarial y el público.

2. Ampliación de la gama de instrumentos de política medioambiental para incluir, impuestos, subsidios y acuerdos voluntarios.

3. Cambio de los modelos de consumo y producción.

4. Aplicación y cumplimiento de una legislación.

5. Cooperación internacional en el marco de la Agenda 21 y el V Programa de Acción Medioambiental.

Además, el Libro blanco de la educación medioambiental del Ministerio de Medio Ambiente de España (1999), señala: "Se deben asumir responsabilidades desde todos los ámbitos sociales. Es preciso afrontar el reto de construir un nuevo modelo de sociedad sostenible en lo ambiental y equitativa en lo social" (p. 7).

En cuanto al desarrollo sostenible, el Libro plantea que la existencia de límites físicos imposibilita un crecimiento sin fin y mejora la calidad de vida. Frente al bienestar sostenido en bienes materiales, manifiesta que es necesaria la solidaridad entre las diferentes generaciones y entre los individuos de cada generación (Ministerio de Medio Ambiente de España, 1999, p. 14).

En la sustentabilidad se contemplan dimensiones, que son clasificaciones que se dan en función de los recursos y mantienen un equilibrio. El número de dimensiones que integran la sustentabilidad varía de acuerdo con los autores. Para Mejía y Ceballos (2016), Hurtado de Mendoza 
(2012), Vega y Ricárdez (2011), Ramírez y Arenas (2007) son 3

dimensiones: económica, ambiental y social. Para García y Menegaz

(2013), las dimensiones son 4: a las anteriores adicionan la dimensión

institucional del desarrollo. Para el año 2010, se incorporó la dimensión

'cultura' para formar parte de las dimensiones de la sustentabilidad, que

propone considerar los diferentes contextos en los que opera la empresa

para comprender la lógica de sustentabilidad propia (Naiman, 2015).

De forma sintética se presentan las dimensiones de la sustentabilidad mayoritariamente apreciadas:

Dimensión económica. Considera que la empresa debe ser rentable y generar utilidades para su propietario o propietarios, así como una mejor distribución de beneficios y las cargas del bienestar, mediante la moderación de su consumo.

Dimensión ambiental. Señala a la empresa como responsable de gestionar y mitigar los impactos ambientales generados por su operación. Respecto a esta dimensión, se revisó la literatura concerniente a la parte ambiental ${ }^{2} \mathrm{y}$ se identificó que existen diversas posturas que abordan lo ambiental de las que se destacan dos: la de los antropocentristas y la de los ecocentristas3.

Dimensión social. Incluye a los grupos formados por empleados, proveedores, clientes y a la comunidad. Se identifica con la justicia social, en lo que respecta a la inclusión y equidad social.

\footnotetext{
${ }^{2}$ El medio ambiente comprende el espacio para que se desarrolle la vida de los organismos vivos denominados bióticos: las bacterias microscópicas, los hongos, la flora, la fauna, y los seres humanos; elementos sin vida llamados abióticos: el aire, el suelo y el agua; así como elementos artificiales creados por el hombre como la urbanización, la cultura y las tradiciones. La suma de los organismos y los elementos a partir de un momento histórico y un lugar específico integran el medioambiente, que puede ser modificado por los humanos (Etecé, 2020).

${ }^{3}$ Existen pensadores que centran su atención en la relación hombre-naturaleza, en la que se preocupan por el ser humano y su bienestar (antropocentristas) y otro grupo que busca reivindicar a la naturaleza por sí misma (ecocentristas). Ambas posturas comulgan en criticar los excesos de la sociedad industrial consumista, la reducción de la naturaleza a materias primas o insumos naturales y a su lógica desarrollista (Lezama y Domínguez, 2006).
} 
Dimensión cultural. Se integra con la propuesta de considerar el contexto donde se localiza la empresa para identificar los rasgos culturales. Exige superar el etnocentrismo, la aceptación y el fomento de la demodiversidad, al reconocer y respetar todas las identidades, lenguas y creencias (García y Menegaz, 2013; Naiman, 2015).

En el presente trabajo se consideran las dimensiones de inicio de la sustentabilidad que son: dimensión económica, ambiental-ecológica y social, y se agrega la dimensión cultural.

Ahora bien, el término 'sustentabilidad' ha evolucionado hasta llegar al término más integrador de 'desarrollo sustentable' (DS), del que han surgido diferentes modelos para abordarlo: modelo de stock de capital del Banco Mundial (Serageldin y Steer, 1994), el modelo de prisma del DS (Spangenberg y Boniot, 1998; Valentin y Spangenberg, 2000), modelo de huevo del DS (Guijt y Mosiseev, 2001) y el modelo main prisma por utilizar el término mente para la dimensión social (Kain, 2003). El propósito de los modelos referidos es disponer de elementos que permitan un referente para evaluar al desarrollo sustentable (Ramírez y Arenas, 2008). En la figura 1 se presenta un resumen de este abordaje conceptual. 
Figura 1. Sustentabilidad, dimensiones y modelos

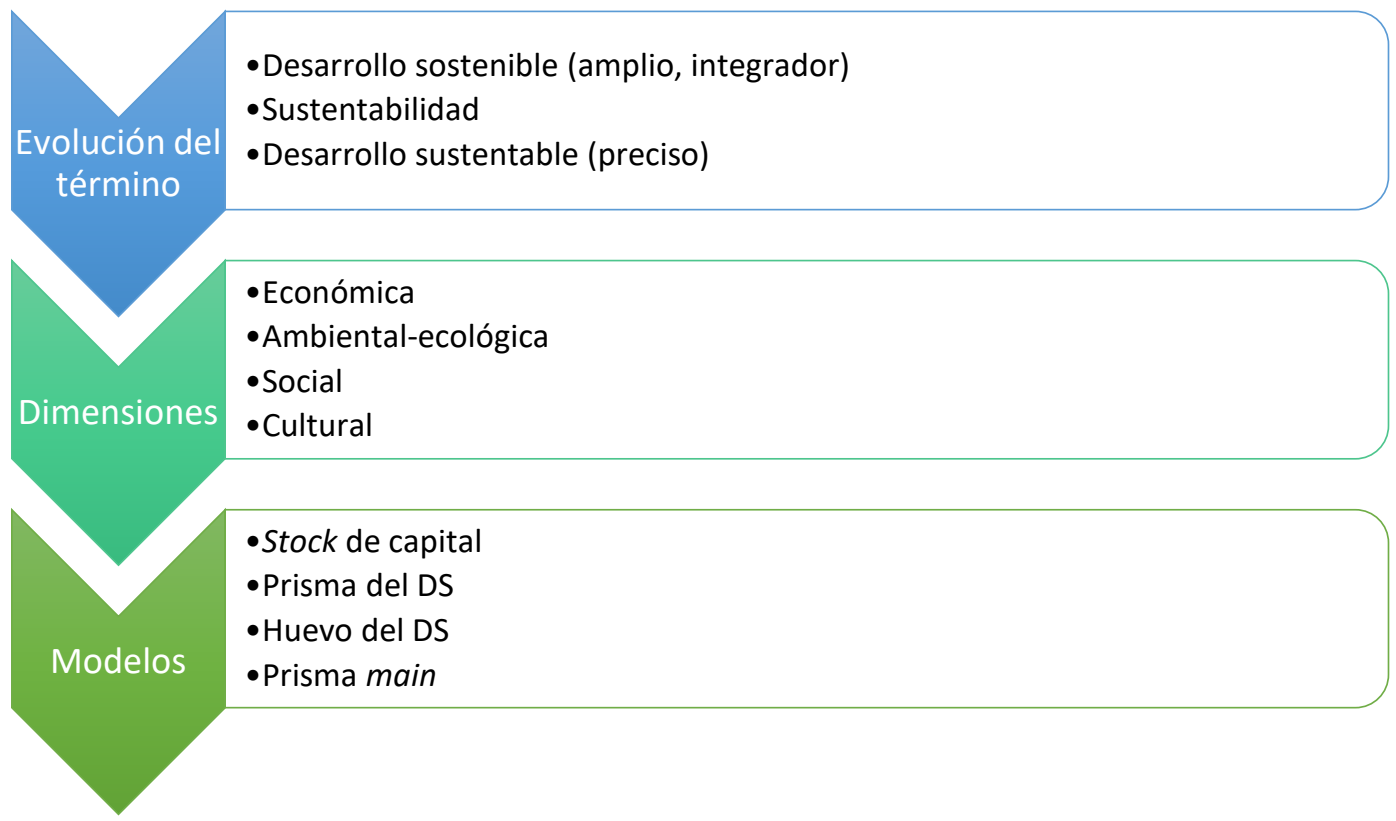

Fuente: elaboración propia.

\section{Contabilidad}

La contabilidad ha ido evolucionando con el fin de cubrir distintas necesidades que han presentado las empresas (Vega y Ricárdez, 2017). Para atender las necesidades que surgen en las empresas de distintos giros, teniendo siempre como base a la contabilidad financiera, han nacido diferentes especializaciones: contabilidad de sociedades, contabilidad de hospitales, contabilidad de hoteles, contabilidad forestal, contabilidad agrícola, contabilidad ganadera, contabilidad forense y contabilidad ambiental, entre otras. A la luz de las Normas de Información Financiera (NIF) (Instituto Mexicano de Contadores Públicos [IMCP], 2021), la contabilidad financiera constituye el punto de partida para las diferentes contabilidades especializadas.

En México, la NIF A-1 define a la contabilidad financiera como 
[...] una técnica que se utiliza para el registro de las operaciones que, afectan económicamente a una entidad y que produce sistemática y estructuradamente información financiera. Las operaciones que afectan económicamente a una entidad incluyen las transacciones, trasformaciones internas y otros eventos. (2021, p. 5)

Esta se obtiene como producto información financiera que se presenta en los denominados estados financieros.

La misma NIF A-1 señala que

[...] la información financiera que emana de la contabilidad [...] es información cuantitativa expresada en unidades monetarias, [...] descriptiva, dado que muestra la posición y desempeño financiero de una entidad [y] su objetivo esencial es ser de utilidad al usuario en la toma de sus decisiones económicas. (IMCP, 2021, p. 5)

La contabilidad ha ampliado su cometido de considerar únicamente el control financiero de las empresas para convertirse en una práctica social institucionalizada (Curvelo, 2011), situación que obliga a reconocer la importancia de los colaboradores como elementos primordiales en las empresas (Morgan, como se citó en Gaffikin, 2006). Por ello, los contadores, además del elemento humano, tienen que atender la naturaleza y seguir trabajando con los aspectos económicos.

Por su parte, para Curvelo (2011) la contabilidad como ciencia social facilita que se integre como parte de ella el reflejar, en términos monetarios, el impacto social y ambiental de las empresas y el desarrollo sustentable, lo que se convierte en un reto para el contador público.

En este contexto, los informes que incorporan las dimensiones social y medioambiental representan en una sociedad democrática un elemento que permite a las empresas dar cuenta de su responsabilidad social (Gray, 1992; Gray et al., 1996). Obedeciendo a esta nueva visión de la 
contabilidad, surgen posturas que señalan la importancia de medir la sustentabilidad y presentarla en la información financiera de forma integrada o separada, con las dimensiones económica, ambiental y social (Jiménez, 2015). Sin embargo, en una apreciación empírica, la dimensión mayormente atendida por la contabilidad es la dimensión ambiental, la cual apoya el surgimiento de la contabilidad ambiental, que aborda únicamente la dimensión medioambiental de la sustentabilidad (al centrar su atención en aspectos ecológicos).

También se pueden identificar indicios que se enfocan en aspectos ambientales (Deniz, 2007), como los elementos que se incorporen a la entidad con el objeto de ser utilizados de forma duradera en su actividad, cuya finalidad principal sea la minimización del impacto medioambiente y la protección y mejora del medio ambiente, incluyendo la reducción o eliminación de la contaminación futura de las operaciones de la entidad, se contabilizarán como parte de los activos. Por consiguiente, la empresa que incorpore el tipo de activos antes mencionados se puede ver beneficiada con ahorros en materiales y materias primas, utilización de materiales reciclables, uso de tecnologías limpias, reducción de costos por desechos, tener ingresos adicionales a los propios de su giro por venta de materiales reciclables (Jiménez, 2013). Lo anterior muestra el antecedente de la contabilidad sustentable.

\section{Contabilidad sustentable}

La contabilidad Sustentable forma parte de las contabilidades especializadas derivadas de la contabilidad financiera. Los dos principales enfoques de que se vale la disciplina contable para captar la realidad y luego elaborar informes son el económico-financiero, considerado como el enfoque tradicional, y el socioambiental (Fernández y Carrara, 2009). 
La sustentabilidad abocada a la contabilidad, es decir la contabilidad sustentable (CS), incluye a las personas sus habilidades, dedicación y experiencias. El comportamiento resultante es el foco de la dimensión social o "capital humano"; el buen manejo de esta dimensión puede ser una ventaja competitiva en la empresa (Jiménez, 2015). Por esto, la contabilidad sustentable presenta cuantitativamente las acciones realizadas por la empresa en las distintas dimensiones de la sustentabilidad.

A partir de la mitad de la década de 1990, las empresas comenzaron a utilizar las cuentas para reflejar los impactos sociales de su operación. Para la década del 2000, las empresas incursionaron con la redacción de informes sustentables, que relataban el impacto de sus actividades en las dimensiones económica, social y ambiental, de forma cuantitativa y cualitativa (Thomson y Bebbington, 2005). Además, empezaron a surgir algunos estándares de sustentabilidad que se pueden asociar a la contabilidad sustentable (Néron, 2010).

La contabilidad sustentable refleja lo propuesto por el informe de sustentabilidad y se puede presentar de forma conjunta o por separado con los informes anuales de la empresa (O’Dwyer y Owen, 2005, citados en Jiménez, 2015).

\section{Elaboración de informes de sustentabilidad}

Los informes de sustentabilidad en lo concerniente a su elaboración tienen como apoyo lo que señala la Iniciativa de Reporte Global (Reporting Initiative [GRI], 2013) y la triple cuenta de resultados, entre otros.

Iniciativa de Reporte Global (Global Reporting Initiative)

El informe de sustentabilidad, a través de su publicación con una propuesta de informes realizada por la Iniciativa Mundial para la 
Elaboración de Informes (GRI, 2002), ha servido de apoyo para dar cuenta de la sustentabilidad, en los informes anuales de la empresa (O’Dwyer y Owen, 2005). La propuesta incluye indicadores definidos que apoyan el rendimiento de cuentas por parte de las empresas en lo referente a la sustentabilidad. Con los indicadores, se tiene un instrumento que apoya en la construcción de la información financiera, complementaria a la tradicionalmente identificada, considerando el desempeño de la empresa económico, ambiental y social. Estos tres aspectos se relacionan con elaboración de informes de triple cuenta de resultados, o triple bottom line, que considera las dimensiones de la sustentabilidad económica, ambiental y social, para exhibir la actuación de las empresas en ellas mismas (figura 2).

Figura 2. indicadores para la elaboración de los reportes de sustentabilidad

\section{Informes de sustentabilidad}

Global Reporting Initiative
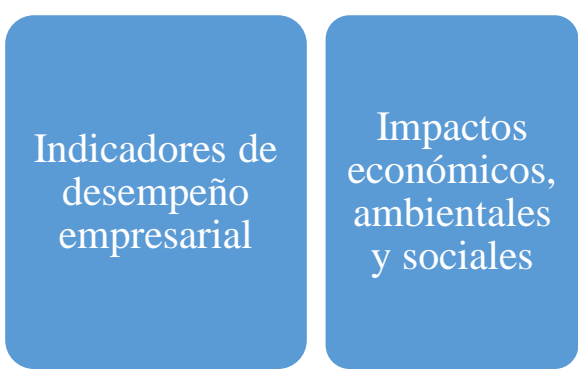

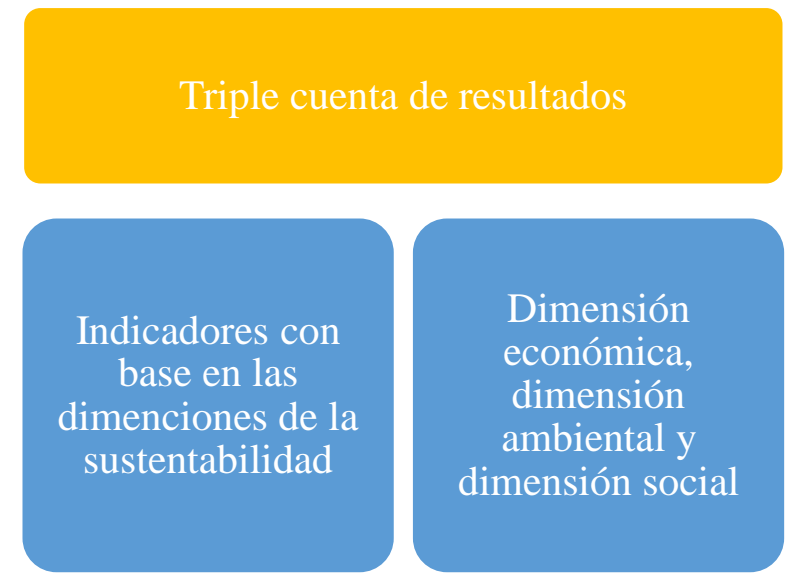

Fuente: elaboración propia con base en la GRI (2002) y Elkington, (1998). 


\section{Dimensiones e indicadores}

La propuesta del GRI sugiere que los indicadores para las 3 dimensiones de la sustentabilidad que incluye como guía no se consideren como una limitante y que las empresas los enriquezcan de acuerdo con necesidades. Así, aporta 11 principios que rigen los informes de sustentabilidad clasificados en 4 grupos (Gómez y Ospina, 2005).

- Primer grupo, Marco del Informe:

1. Transparencia

2. Globalidad

3. Auditabilidad

- Segundo grupo, Decisiones del Contenido del Informe:

1. Exhaustividad

2. Relevancia

3. Contexto de sostenibilidad

- Tercer grupo, Calidad y Veracidad:

1. Precisión

2. Neutralidad

3. Comparabilidad

- Cuarto grupo, Garantía en el Acceso y la Disponibilidad del Informe:

1. Claridad

2. Periodicidad

Si las empresas deciden presentar la información con base en los indicadores mencionados arriba, estarán cumpliendo con informar sobre la visión y la estrategia de la empresa en relación con la sustentabilidad, siempre y cuando se expongan los siguientes aspectos:

- Exposición de la visión y la estrategia. Declaración firmada por las máximas autoridades de la empresa, donde se da a conocer que el 
informe de sustentabilidad ha sido elaborado de conformidad con la guía del GRI.

- Presentar el perfil de la organización, con la descripción de las principales partes interesadas (stakeholders). Perfil de la organización, alcance del informe y perfil del informe.

- Describir la estructura de gobierno, políticas y sistemas de gestión. Estructura de gobierno, compromiso con las partes interesadas, políticas globales y sistemas de gestión incluye, indicadores centrales (core) ${ }^{4}$, adicionales 5 e integrados ${ }^{6}$ (Gómez y Ospina, 2005).

Las empresas tienen dos alternativas para presentar sus informes: la opción esencial y la opción exhaustiva. La primera se integra con los elementos principales de un reporte o memoria de sustentabilidad y abarca los aspectos económicos, ambientales y sociales que inciden en las decisiones. La segunda opción contempla los elementos de la primera y adiciona otros relacionados con la estrategia, el análisis, el gobierno, la ética y la integridad de las organizaciones. La guía G4 del GRI se integra por tres categorías: económica, medio ambiente y desempeño social, con sus correspondientes aspectos e indicadores, y en el caso de la de desempeño social con 4 subcategorías (figura 3).

\footnotetext{
${ }^{4}$ Indicador relevante para la mayoría de las empresas informantes y de interés para la mayoría de las partes interesadas (Gómez y Ospina, 2005).

${ }^{5}$ Indicadores que no son relevantes para la mayoría de las empresas informantes y de interés para la mayoría de las partes interesadas (Gómez y Ospina, 2005).

${ }^{6}$ Indicadores que no alcanzan a identificarse con las dimensiones de información (económica, social y ambiental) o que podrían relacionarse de manera directa con dos o más de estas dimensiones (Gómez y Ospina, 2005).
} 
Figura 3. Informe de sustentabilidad de acuerdo con el GRI-G4

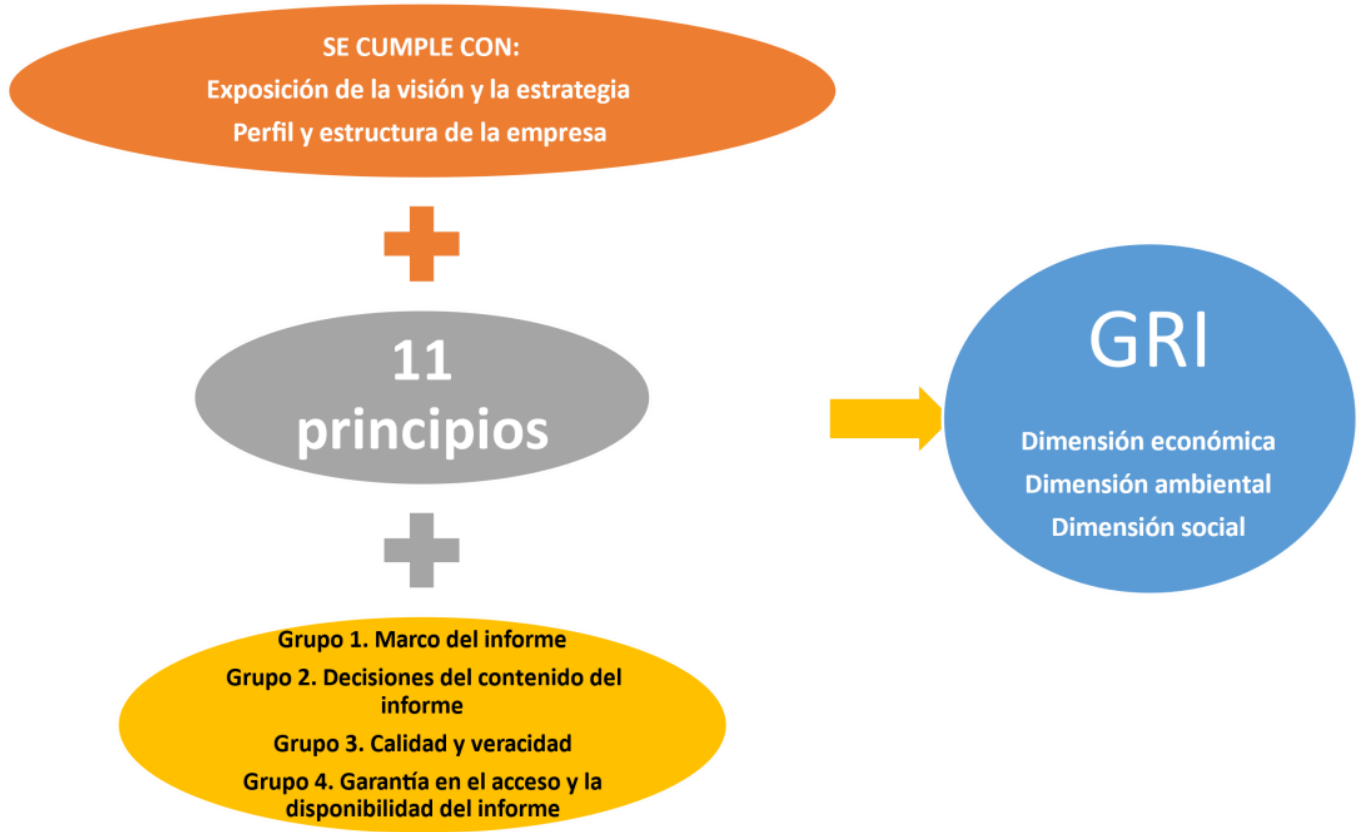

Fuente: elaboración propia con base en la GRI (2013).

\section{Indicadores de la GRI (2013), versión G4}

Los indicadores propuestos por GRI Versión 4 en la categoría economía son los que se incluyen en la tabla 1 y se agrupan en presencia en el mercado, consecuencias económicas indirecta, prácticas de adquisición.

Tabla 1. Indicadores GRI G4 categoría económica

\begin{tabular}{|c|c|}
\hline & $\begin{array}{c}\text { Categoría económica } \\
\text { Aspecto }\end{array}$ \\
\hline $\begin{array}{c}\text { Desempeño } \\
\text { económico }\end{array}$ & $\begin{array}{c}\text { Valor económico directo generado y distribuido } \\
\text { Consecuencias económicas y otros riesgos y oportunidades para las actividades de } \\
\text { la organización que se derivan del cambio climático }\end{array}$ \\
\hline $\begin{array}{c}\text { Presencia en el } \\
\text { mercado }\end{array}$ & $\begin{array}{r}\text { Cobertura de las obligaciones de la organización derivadas de su plan de } \\
\text { prestaciones }\end{array}$ \\
\hline & Ayudas económicas otorgadas por entes del gobierno \\
\hline
\end{tabular}

\section{Revista Activos}

ISSN: 0124-5805 | e-ISSN: 2500-5278 | DOI: https://doi.org/10.15332/25005278

Vol. 19 N. ${ }^{\circ} 1$ | enero-junio de 2021 


\begin{tabular}{|c|c|}
\hline & \multicolumn{1}{c|}{$\begin{array}{c}\text { Categoría económica } \\
\text { Aspecto }\end{array}$} \\
\hline & $\begin{array}{r}\text { Porcentaje de altos directivos procedentes de la comunidad local en lugares donde } \\
\text { se desarrollan operaciones significativas }\end{array}$ \\
\hline $\begin{array}{c}\text { Consecuencias } \\
\text { económicas } \\
\text { indirectas }\end{array}$ & Desarrollo e impacto de la inversión en infraestructuras y los tipos de servicios \\
\hline $\begin{array}{c}\text { Prácticas de } \\
\text { adquisición }\end{array}$ & Porcentaje del gasto en los lugares con operaciones significativas que corresponde \\
\hline
\end{tabular}

Fuente: elaboración propia con base en GRI G4 (2013, pp. 48-83).

Los indicadores propuestos por GRI Versión 4 en la categoría medioambiental se integran en la tabla 2. Se presentan según los relacionados con los siguientes elementos: energía, agua, biodiversidad, emisiones, efluentes y residuos, productos y servicios, cumplimiento regulatorio, transporte, evaluación ambiental de los proveedores y mecanismos de reclamación en materia ambiental.

Tabla 2. Indicadores GRI G4 categoría medio ambiente

\begin{tabular}{|c|c|}
\hline & $\begin{array}{c}\text { Categoría medio ambiente } \\
\text { Aspectos } \\
\text { Materiales }\end{array}$ \\
\hline Materiales por peso o volumen \\
\hline Porcentaje de los materiales utilizados que son materiales reciclados \\
Cnergía
\end{tabular}

Revista Activos

ISSN: 0124-5805 | e-ISSN: 2500-5278 | DOI: https://doi.org/10.15332/25005278

Vol. 19 N.o 1 | enero-junio de 2021 


\begin{tabular}{|c|c|}
\hline \multicolumn{2}{|r|}{ Categoría medio ambiente } \\
\hline \multicolumn{2}{|r|}{ Aspectos } \\
\hline \multicolumn{2}{|r|}{$\begin{array}{c}\text { Descripción de los impactos más significativos en la biodiversidad de áreas } \\
\text { protegidas o áreas de alta biodiversidad no protegidas, derivados de las } \\
\text { actividades, los productos y los servicios }\end{array}$} \\
\hline \multicolumn{2}{|r|}{ Hábitats protegidos o restaurados } \\
\hline & $\begin{array}{c}\text { Número de especies incluidas en la lista roja de la uicn y en listados nacionales } \\
\text { de conservación cuyos hábitats se encuentran en áreas afectadas por las } \\
\text { operaciones, según el nivel de peligro de extinción de la especie }\end{array}$ \\
\hline \multirow{7}{*}{ Emisiones } & Emisiones directas de gases de efecto invernadero (alcance 1) \\
\hline & $\begin{array}{l}\text { Emisiones indirectas de gases de efecto invernadero al generar energía } \\
\text { (alcance } 2 \text { ) }\end{array}$ \\
\hline & Otras emisiones indirectas de gases de efecto invernadero (alcance 3 ) \\
\hline & Intensidad de las emisiones de gases de efecto invernadero \\
\hline & Reducción de las emisiones de gases de efecto invernadero \\
\hline & Emisiones de sustancias que agotan el ozono \\
\hline & Nox, Sox y otras emisiones atmosféricas significativas \\
\hline \multirow{5}{*}{ Efluentes y residuos } & Vertido total de aguas, según su calidad y destino \\
\hline & Peso total de los residuos, según tipo y método de tratamiento \\
\hline & Número y volumen totales de los derrames significativos \\
\hline & $\begin{array}{l}\text { Peso de los residuos transportados, importados, exportados o tratados que se } \\
\text { consideran peligrosos en virtud de los anexos i, ii, iii y viii del convenio de } \\
\text { Basilea 2, y porcentaje de residuos transportados internacionalmente }\end{array}$ \\
\hline & $\begin{array}{l}\text { Identificación, tamaño, estado de protección y valor de biodiversidad de las } \\
\text { masas de agua y los hábitats relacionados afectados significativamente por } \\
\text { vertidos y escorrentia procedentes de la organización }\end{array}$ \\
\hline \multirow[b]{2}{*}{ Productos y servicios } & Grado de mitigación del impacto ambiental de los productos y servicios \\
\hline & $\begin{array}{l}\text { Porcentaje de los productos vendidos y sus materiales de embalaje que se } \\
\text { recuperan al final de su vida útil, por categorías de productos }\end{array}$ \\
\hline $\begin{array}{l}\text { Cumplimiento } \\
\text { Regulatorio }\end{array}$ & $\begin{array}{l}\text { Valor monetario de las multas significativas y número de sanciones no } \\
\text { monetarias por incumplimiento de la legislación y la normativa ambiental }\end{array}$ \\
\hline Transporte & $\begin{array}{l}\text { Impactos ambientales significativos del transporte de productos y otros bienes } \\
\text { y materiales utilizados para las actividades de la organización, así como del } \\
\text { transporte de personal }\end{array}$ \\
\hline General & Desglose de los gastos y las inversiones ambientales \\
\hline \multirow{2}{*}{$\begin{array}{l}\text { Evaluación ambiental } \\
\text { de los Proveedores }\end{array}$} & $\begin{array}{l}\text { Porcentaje de nuevos proveedores que se examinaron en función de criterios } \\
\qquad \text { ambientales }\end{array}$ \\
\hline & $\begin{array}{l}\text { Impactos ambientales negativos significativos, reales y potenciales, en la } \\
\text { cadena de suministro, y medidas al respecto }\end{array}$ \\
\hline
\end{tabular}

Revista Activos

ISSN: 0124-5805 | e-ISSN: 2500-5278 | DOI: https://doi.org/10.15332/25005278

Vol. 19 N.o 1 | enero-junio de 2021 


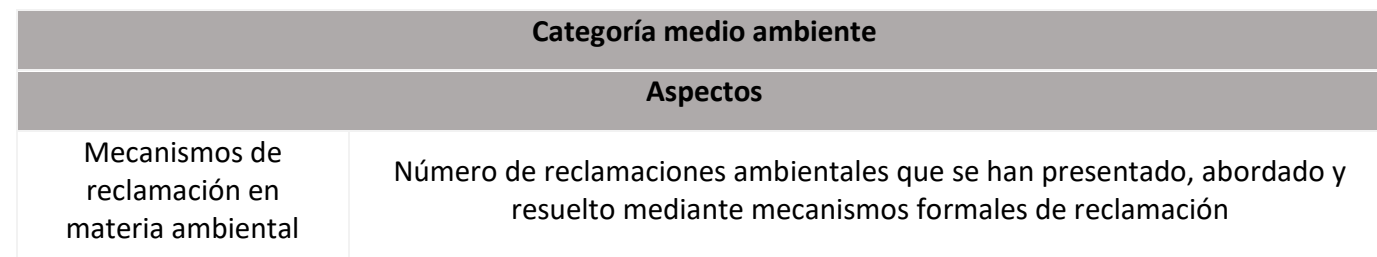

Fuente: elaboración propia con base en la GRI G4 (2013).

Los indicadores propuestos por GRI Versión 4 en la categoría de desempeño social se incluyen en la tabla 3 anexa. Se integran por las siguientes subcategorías: prácticas laborales y trabajo digno (empleo, relaciones entre los trabajadores y la dirección, salud y seguridad en el trabajo, capacitación y educación, diversidad e igualdad de oportunidades, igualdad de retribución entre mujeres y hombres, evaluación de las prácticas laborales de los proveedores y mecanismos de reclamación sobre prácticas laborales). En la subcategoría derechos humanos se incluye: inversión, no discriminación, libertad de asociación y negociación colectiva, trabajo infantil, trabajo forzoso, medidas de seguridad, derechos de la población indígena, evaluación de los proveedores en materia de derechos humanos y mecanismos de reclamación en materia de derechos humanos). En la subcategoría sociedad están las comunidades locales, lucha contra la corrupción, política pública, prácticas de competencia desleal, cumplimiento regulatorio, evaluación del impacto social de los proveedores y mecanismos de reclamación del impacto social. Para la subcategoría de responsabilidad del producto se incluyen salud y seguridad de los clientes, etiquetado de los productos y servicios, comunicaciones de mercadotecnia, privacidad de los clientes y cumplimiento regulatorio. 


\section{Tabla 3. Indicadores GRI G4 categoría desempeño social}

\begin{tabular}{|c|c|}
\hline \multicolumn{2}{|r|}{ Categoría desempeño social } \\
\hline \multicolumn{2}{|r|}{ Subcategoría: prácticas laborales y trabajo digno } \\
\hline \multicolumn{2}{|r|}{ Aspectos } \\
\hline \multirow{3}{*}{ Empleo } & $\begin{array}{c}\text { Número y tasa de contrataciones y rotación media de empleados, desglosados } \\
\text { por grupo etario, sexo y región }\end{array}$ \\
\hline & $\begin{array}{l}\text { Prestaciones sociales para los empleados a jornada completa que no se ofrecen } \\
\text { a los empleados temporales o a media jornada, desglosadas por ubicaciones } \\
\text { significativas de actividad }\end{array}$ \\
\hline & $\begin{array}{l}\text { Índices de reincorporación al trabajo y de retención tras la baja por maternidad } \\
\text { o paternidad, desglosados por sexo }\end{array}$ \\
\hline $\begin{array}{l}\text { Relaciones entre los } \\
\text { trabajadores y la } \\
\text { dirección }\end{array}$ & $\begin{array}{l}\text { Plazos mínimos de preaviso de cambios operativos y posible inclusión de estos } \\
\qquad \text { en los convenios colectivos. }\end{array}$ \\
\hline \multirow{4}{*}{$\begin{array}{l}\text { Salud y seguridad en } \\
\text { el trabajo }\end{array}$} & $\begin{array}{l}\text { Porcentaje de trabajadores que está representado en comités formales de } \\
\text { seguridad y salud conjuntos para dirección y empleados, establecidos para } \\
\text { ayudar a controlar y asesorar sobre programas de seguridad y salud laboral }\end{array}$ \\
\hline & $\begin{array}{l}\text { Tipo y tasa de lesiones, enfermedades profesionales, días perdidos, absentismo } \\
\text { y número de víctimas mortales relacionadas con el trabajo por región y por } \\
\text { sexo }\end{array}$ \\
\hline & $\begin{array}{l}\text { Trabajadores cuya profesión tiene una incidencia o un riesgo elevados de } \\
\text { enfermedad }\end{array}$ \\
\hline & Asuntos de salud y seguridad cubiertos en acuerdos formales con los sindicatos \\
\hline \multirow{3}{*}{$\begin{array}{l}\text { Capacitación y } \\
\text { educación }\end{array}$} & $\begin{array}{l}\text { Promedio de horas de capacitación anuales por empleado, desglosado por sexo } \\
\text { y por categoría laboral }\end{array}$ \\
\hline & $\begin{array}{l}\text { Programas de gestión de habilidades y de formación continua que fomentan la } \\
\text { empleabilidad de los trabajadores y les ayudan a gestionar el final de sus } \\
\text { carreras profesionales }\end{array}$ \\
\hline & $\begin{array}{l}\text { Porcentaje de empleados que reciben evaluaciones regulares del desempeño y } \\
\text { de desarrollo profesional, desglosado por sexo y por categoría profesional }\end{array}$ \\
\hline $\begin{array}{l}\text { Diversidad e igualdad } \\
\text { de oportunidades }\end{array}$ & $\begin{array}{l}\text { Composición de los órganos de gobierno y desglose de la plantilla por categoría } \\
\text { profesional y sexo, edad, pertenencia a minorías y otros indicadores de } \\
\text { diversidad }\end{array}$ \\
\hline $\begin{array}{l}\text { Igualdad de } \\
\text { retribución entre } \\
\text { mujeres y hombres }\end{array}$ & $\begin{array}{c}\text { Relación entre el salario base de los hombres con respecto al de las mujeres, } \\
\text { desglosada por categoría profesional y por ubicaciones significativas de } \\
\text { actividad }\end{array}$ \\
\hline \multirow{2}{*}{$\begin{array}{l}\text { Evaluación de las } \\
\text { prácticas laborales de } \\
\text { los proveedores }\end{array}$} & $\begin{array}{l}\text { Porcentaje de nuevos proveedores que se examinaron en función de criterios } \\
\text { relativos a las prácticas laborales }\end{array}$ \\
\hline & $\begin{array}{c}\text { Impactos negativos significativos, reales y potenciales, en las prácticas laborales } \\
\text { en la cadena de suministro, y medidas al respecto }\end{array}$ \\
\hline
\end{tabular}

\section{Revista Activos}

ISSN: 0124-5805 | e-ISSN: 2500-5278 | DOI: https://doi.org/10.15332/25005278

Vol. 19 N.o 1 | enero-junio de 2021 


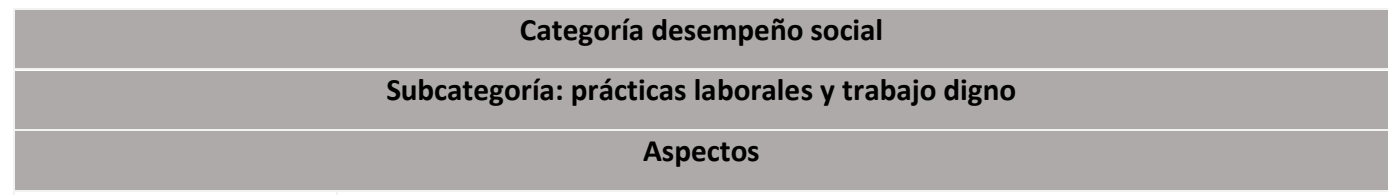

Mecanismos de reclamación sobre prácticas laborales
Número de reclamaciones sobre prácticas laborales que se han presentado, abordado y resuelto mediante mecanismos formales de reclamación

Subcategoría: derechos humanos

\section{Aspectos}

\begin{tabular}{|c|c|}
\hline \multirow{2}{*}{ Inversión } & $\begin{array}{l}\text { Número y porcentaje de contratos y acuerdos de inversión significativos que } \\
\text { incluyen cláusulas de derechos humanos o que han sido objeto de análisis en } \\
\text { materia de derechos humanos }\end{array}$ \\
\hline & $\begin{array}{l}\text { Horas de formación de los empleados sobre políticas y procedimientos } \\
\text { relacionados con aquellos aspectos de los derechos humanos relevantes para } \\
\text { sus actividades, incluido el porcentaje de empleados capacitados }\end{array}$ \\
\hline No discriminación & Número de casos de discriminación y medidas correctivas adoptadas \\
\hline $\begin{array}{l}\text { Libertad de asociación } \\
\text { y negociación } \\
\text { colectiva }\end{array}$ & $\begin{array}{l}\text { Identificación de centros y proveedores significativos en los que la libertad de } \\
\text { asociación y el derecho de acogerse a convenios colectivos pueden infringirse o } \\
\text { estar amenazados, y medidas adoptadas para defender estos derechos }\end{array}$ \\
\hline Trabajo infantil & $\begin{array}{l}\text { Identificación de centros y proveedores con un riesgo significativo de casos de } \\
\text { explotación infantil, y medidas adoptadas para contribuir a la abolición de la } \\
\text { explotación infantil }\end{array}$ \\
\hline Trabajo forzoso & $\begin{array}{l}\text { Centros y proveedores con un riesgo significativo de ser origen de episodios de } \\
\text { trabajo forzoso, y medidas adoptadas para contribuir a la eliminación de todas } \\
\text { las formas de trabajo forzoso }\end{array}$ \\
\hline Medidas de seguridad & $\begin{array}{c}\text { Porcentaje del personal de seguridad que ha recibido capacitación sobre las } \\
\text { políticas o procedimientos de la organización en materia de derechos humanos } \\
\text { relevantes para las operaciones }\end{array}$ \\
\hline $\begin{array}{l}\text { Derechos de la } \\
\text { población indígena }\end{array}$ & $\begin{array}{l}\text { Número de casos de violación de los derechos de los pueblos indígenas y } \\
\text { medidas adoptadas }\end{array}$ \\
\hline Evaluación & $\begin{array}{l}\text { Número y porcentaje de centros que han sido objeto de exámenes o } \\
\text { evaluaciones de impactos en materia de derechos humanos }\end{array}$ \\
\hline \multirow{2}{*}{$\begin{array}{l}\text { Evaluación de los } \\
\text { proveedores en } \\
\text { materia de derechos } \\
\text { humanos }\end{array}$} & $\begin{array}{l}\text { Porcentaje de nuevos proveedores que se examinaron en función de criterios } \\
\text { relativos a los derechos humanos }\end{array}$ \\
\hline & $\begin{array}{l}\text { Impactos negativos significativos en materia de derechos humanos, reales y } \\
\text { potenciales, en la cadena de suministro, y medidas adoptadas }\end{array}$ \\
\hline $\begin{array}{l}\text { Mecanismos de } \\
\text { reclamación en } \\
\text { materia de derechos } \\
\text { humanos }\end{array}$ & $\begin{array}{l}\text { Número de reclamaciones sobre derechos humanos que se han presentado, } \\
\text { abordado y resuelto mediante mecanismos formales de reclamación }\end{array}$ \\
\hline \multicolumn{2}{|r|}{ Subcategoría: sociedad } \\
\hline & Aspectos \\
\hline
\end{tabular}

Revista Activos

ISSN: 0124-5805 | e-ISSN: 2500-5278 | DOI: https://doi.org/10.15332/25005278

Vol. 19 N.o 1 | enero-junio de 2021 


\begin{tabular}{|c|c|}
\hline \multicolumn{2}{|r|}{ Categoría desempeño social } \\
\hline \multicolumn{2}{|r|}{ Subcategoría: prácticas laborales y trabajo digno } \\
\hline \multicolumn{2}{|r|}{ Aspectos } \\
\hline \multirow{2}{*}{ Comunidades locales } & $\begin{array}{l}\text { Porcentaje de centros donde se han implantado programas de desarrollo, } \\
\text { evaluaciones de impactos y participación de la comunidad local }\end{array}$ \\
\hline & $\begin{array}{c}\text { Centros de operaciones con efectos negativos significativos, posibles o reales, } \\
\text { sobre las comunidades locales }\end{array}$ \\
\hline \multirow{3}{*}{$\begin{array}{l}\text { Lucha contra la } \\
\text { corrupción }\end{array}$} & $\begin{array}{l}\text { Número y porcentaje de centros en los que se han evaluado los riesgos } \\
\text { relacionados con la corrupción y riesgos significativos detectados }\end{array}$ \\
\hline & $\begin{array}{l}\text { Políticas y procedimientos de comunicación y capacitación sobre la lucha contra } \\
\text { la corrupción }\end{array}$ \\
\hline & Casos confirmados de corrupción y medidas adoptadas \\
\hline Política pública & Valor de las contribuciones políticas, por país y destinatario \\
\hline $\begin{array}{l}\text { Prácticas de } \\
\text { competencia desleal }\end{array}$ & $\begin{array}{c}\text { Número de demandas por competencia desleal, prácticas monopolísticas o } \\
\text { contra la libre competencia y resultado de las mismas }\end{array}$ \\
\hline $\begin{array}{l}\text { Cumplimiento } \\
\text { regulatorio }\end{array}$ & $\begin{array}{l}\text { Valor monetario de las multas significativas y número de sanciones no } \\
\text { monetarias por incumplimiento de la legislación y la normativa }\end{array}$ \\
\hline \multirow{2}{*}{$\begin{array}{l}\text { Evaluación del } \\
\text { impacto social de los } \\
\text { proveedores }\end{array}$} & $\begin{array}{l}\text { Porcentaje de nuevos proveedores que se examinaron en función de criterios } \\
\text { relacionados con la repercusión social }\end{array}$ \\
\hline & $\begin{array}{l}\text { Impactos negativos significativos y potenciales para la sociedad en la cadena de } \\
\text { suministro, y medidas adoptadas }\end{array}$ \\
\hline $\begin{array}{l}\text { Mecanismos de } \\
\text { reclamación del } \\
\text { impacto social }\end{array}$ & $\begin{array}{l}\text { Número de reclamaciones sobre impactos sociales que se han presentado, } \\
\text { abordado y resuelto mediante mecanismos formales de reclamación }\end{array}$ \\
\hline \multicolumn{2}{|r|}{ Subcategoría: responsabilidad del producto } \\
\hline \multicolumn{2}{|r|}{ Aspectos } \\
\hline \multirow[b]{2}{*}{$\begin{array}{l}\text { Salud y seguridad de } \\
\text { los clientes }\end{array}$} & $\begin{array}{l}\text { Porcentaje de categorías de productos y servicios significativos cuyos impactos } \\
\text { en materia de salud y seguridad se han evaluado para promover mejoras }\end{array}$ \\
\hline & $\begin{array}{l}\text { Número de incidentes derivados del incumplimiento de la normativa o de los } \\
\text { códigos voluntarios relativos a los impactos de los productos y servicios en la } \\
\text { salud y la seguridad durante su ciclo de vida, desglosados en función del tipo de } \\
\text { resultado de dichos incidentes }\end{array}$ \\
\hline \multirow{4}{*}{$\begin{array}{l}\text { Etiquetado de los } \\
\text { productos y servicios }\end{array}$} & $\begin{array}{l}\text { Tipo de información que requieren los procedimientos de la organización } \\
\text { relativos a la información y el etiquetado de sus productos y servicios, y } \\
\text { porcentaje de categorías de productos y servicios significativos que están } \\
\text { sujetas a tales requisitos }\end{array}$ \\
\hline & $\begin{array}{l}\text { Número de incumplimientos de la regulación y de los códigos voluntarios } \\
\text { relativos a la información y al etiquetado de los productos y servicios, } \\
\text { desglosados en función del tipo de resultado }\end{array}$ \\
\hline & Resultados de las encuestas para medir la satisfacción de los clientes \\
\hline & Venta de productos prohibidos o en litigio \\
\hline
\end{tabular}

Revista Activos

ISSN: 0124-5805 | e-ISSN: 2500-5278 | DOI: https://doi.org/10.15332/25005278

Vol. 19 N.o 1 | enero-junio de 2021 


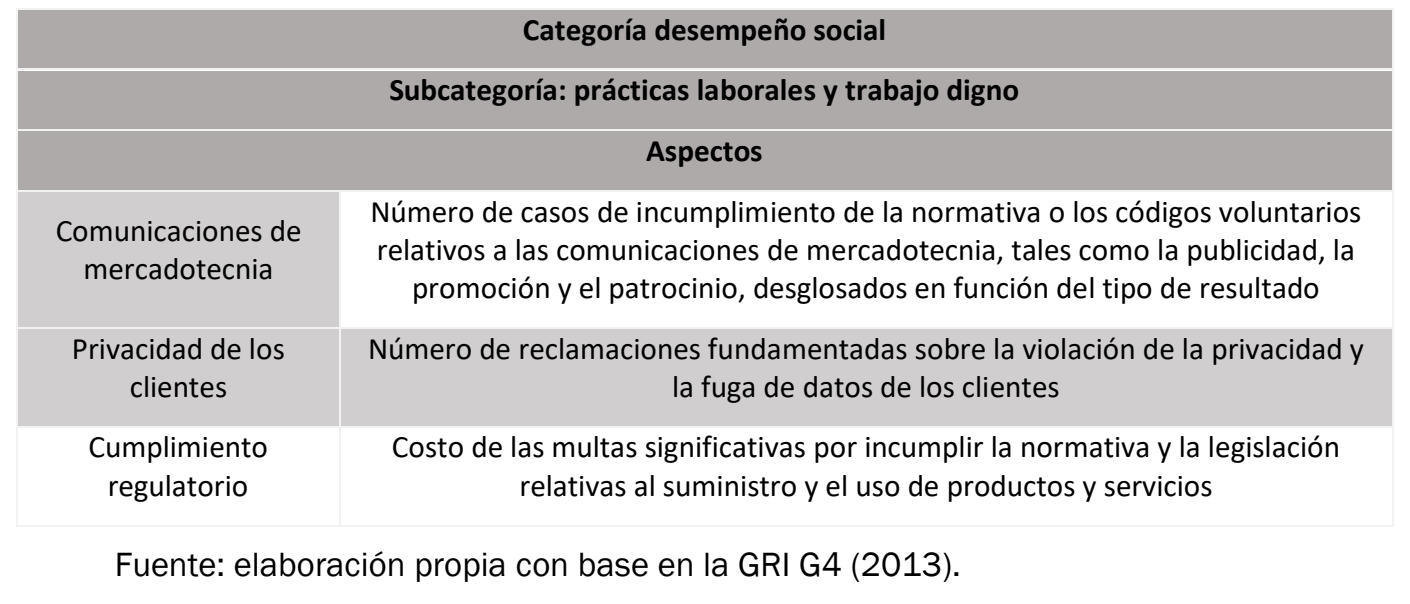

Como se puede apreciar en las tablas 1, 2 y 3 cada aspecto incluye de forma sintética su correspondiente o correspondientes indicadores, que apoyan en la elaboración de la memoria o reporte de sustentabilidad. A continuación se presenta el referente a la triple cuenta de resultados que también apoya para la elaboración de los reportes de sostenibilidad.

\section{Triple cuenta de resultados (TCR) o triple bottom line (TBL)}

Elkington (1998) da a conocer el concepto de 'triple cuenta de resultados' para reconocer en las empresas la creación de valor económico, social y ambiental, y las lleva a mostrarse como empresas sostenibles. Así, los valores económico, social y ambiental mantienen un equilibrio altamente relacionado con la ética y la responsabilidad.

Según García et al. (2015, p. 70), la triple cuenta de resultados en 1998 fue acogida en el repertorio conceptual de las Naciones Unidas como una estrategia de negocio para desarrollo de la sostenibilidad. Lo anterior requiere que las empresas adopten un modelo de negocios, que incluya beneficios económicos, sociales y ambientales, y que, con la adopción de ese modelo, se responda a las exigencias actuales de la economía global. La triple cuenta de resultados según García (2015), identifica valores como inversiones y procesos que la empresa adopta para evitar resultados 
negativos por el desarrollo de su actividad y para crear valor económico, social y medioambiental. Permite a las empresas construir información con parámetros relacionados con la actuación empresarial económica, social y medioambiental. Por esto, considera tres líneas en constante movimiento por los cambios del entorno; los cambios pueden presentarse de forma individual o simultáneamente. Una de las líneas representa a la sociedad, otra a la economía y la otra el medioambiente. En la consideración que la sociedad está relacionada con la economía y con el medioambiente.

El objetivo de la TCR es medir el desempeño financiero, social y ambiental de una empresa durante un periodo de tiempo. Se conforma por tres $\mathrm{P}$, por sus siglas en inglés: ganancias (pickings), personas (people) y el planeta (planet) (Slaper y Hill, 2011, citados en Jiménez, 2015). Además, la TCR considera incorporar los elementos de capital humano y capital natural en la gestión de costos tradicionales de la empresa (Elkington, 1998). Autores como Kleindorfer, et al. (2005, citados en Jiménez, 2015) tienen una perspectiva amplia de la TCR integrando en las tres P parte de la cultura corporativa, estrategia y las operaciones de una empresa.

Para Norman y MacDonald, (2004) la TCR considera que los datos que se obtienen de empleados, clientes, proveedores, comunidad y otras partes interesadas deben ser medidos, calculados y reportados de forma similar a la de los resultados financieros de una empresa. Los elementos que se toman en consideración para integrar cada grupo, son los siguientes:

- Medioambientales. energía, agua, materiales utilizados, tecnologías limpias, emisiones y residuos, diseños operacionales ecoeficientes, nuevos productos y servicios, ecotecnia e impacto en el sistema de vida. 
- Económicos. aumento del beneficio, productividad, beneficios marginales crecientes, retorno de la inversión, costo del capital, valoración de la empresa, riesgos asumidos por la dirección y crédito mercantil.

- Sociales. impacto social y comunitario, salud y seguridad laboral, igualdad de oportunidades, educación, capacitación, reconocimiento social y pensiones (García, 2015).

La tabla 4 muestra la estructura de la matriz para la TCR. Esta incluye los grupos de propietarios, empleados, clientes, proveedores, competencia, comunidad, humanidad, generaciones futuras y mundo natural; con sus respectivos indicadores para economía y finanzas, medioambienteecología y acción social.

Los beneficios de la aplicación de TCR se reflejan en el mercado, imagen, productividad, facilidad de acceso al capital, disminución de costos de capital y mejora organizativa.

Tabla 4. Matriz de información TCR

\begin{tabular}{|c|c|c|c|c|c|}
\hline Grupo & $\begin{array}{l}\text { Economía } \\
\text { y finanzas }\end{array}$ & $\begin{array}{l}\text { Medio } \\
\text { ambiente- } \\
\text { ecología }\end{array}$ & Acción social & $\begin{array}{l}\text { Total, } \\
\text { resultado de } \\
\text { la suma de } \\
\text { los } \\
\text { beneficios } \\
\text { totales } \\
\text { obtenidos }\end{array}$ & $\begin{array}{l}\text { Total, } \\
\text { resultado de } \\
\text { la suma de } \\
\text { los costos } \\
\text { totales } \\
\text { incurridos }\end{array}$ \\
\hline $\begin{array}{l}\text { Grupo de } \\
\text { Interés }\end{array}$ & $\begin{array}{l}\text { Se integra por } \\
\text { los costos del } \\
\text { impacto del } \\
\text { desarrollo } \\
\text { económico de la } \\
\text { empresa. }\end{array}$ & $\begin{array}{l}\text { Se integra por } \\
\text { los costos del } \\
\text { impacto } \\
\text { medioambiental } \\
\text { de la empresa. }\end{array}$ & $\begin{array}{c}\text { Se integra por } \\
\text { los costos del } \\
\text { impacto de la } \\
\text { empresa en la } \\
\text { sociedad }\end{array}$ & & \\
\hline Propietarios & $\begin{array}{l}\text { Retorno de la } \\
\text { inversión. valor } \\
\text { de la Acción. }\end{array}$ & $\begin{array}{l}\text { Reducción del } \\
\text { riesgo. Uso } \\
\text { racional de los } \\
\text { recursos. }\end{array}$ & $\begin{array}{c}\text { Imagen pública. } \\
\text { Prácticas éticas } \\
\text { y legales. }\end{array}$ & & \\
\hline Empleados & $\begin{array}{l}\text { Beneficios } \\
\text { sociales }\end{array}$ & $\begin{array}{c}\text { Niveles de riesgo } \\
\text { laboral }\end{array}$ & $\begin{array}{c}\text { Desarrollo } \\
\text { profesional, }\end{array}$ & & \\
\hline
\end{tabular}




\begin{tabular}{|c|c|c|c|c|c|}
\hline Grupo & $\begin{array}{l}\text { Economía } \\
\text { y finanzas }\end{array}$ & $\begin{array}{l}\text { Medio } \\
\text { ambiente- } \\
\text { ecología }\end{array}$ & Acción social & $\begin{array}{l}\text { Total, } \\
\text { resultado de } \\
\text { la suma de } \\
\text { los } \\
\text { beneficios } \\
\text { totales } \\
\text { obtenidos }\end{array}$ & $\begin{array}{l}\text { Total, } \\
\text { resultado de } \\
\text { la suma de } \\
\text { los costos } \\
\text { totales } \\
\text { incurridos }\end{array}$ \\
\hline & & & $\begin{array}{c}\text { cultura } \\
\text { corporativa }\end{array}$ & & \\
\hline Clientes & $\begin{array}{l}\text { Precio, Calidad, } \\
\text { Valor añadido } \\
\text { basado en el } \\
\text { producto o } \\
\text { servicios }\end{array}$ & $\begin{array}{l}\text { Productos o } \\
\text { servicios seguros } \\
\text { y respetuosos } \\
\text { con el medio } \\
\text { ambiente }\end{array}$ & $\begin{array}{c}\text { Prácticas éticas } \\
\text { y } \\
\text { responsabilidad } \\
\text { social }\end{array}$ & & \\
\hline Proveedores & $\begin{array}{c}\text { Precios, } \\
\text { condiciones de } \\
\text { pago }\end{array}$ & $\begin{array}{c}\text { Compartir } \\
\text { estrategia y } \\
\text { tecnología } \\
\text { medioambiental }\end{array}$ & $\begin{array}{l}\text { Relaciones } \\
\text { éticas }\end{array}$ & & \\
\hline Competencia & $\begin{array}{l}\text { Competitividad, } \\
\text { prácticas de } \\
\text { mercado libre }\end{array}$ & $\begin{array}{l}\text { Tecnología y } \\
\text { principios } \\
\text { compartidos }\end{array}$ & Ética y legalidad & & \\
\hline Comunidad & $\begin{array}{l}\text { Estabilidad } \\
\text { financiera, } \\
\text { filantropía }\end{array}$ & $\begin{array}{l}\text { Niveles de } \\
\text { riesgo, impacto } \\
\text { ambiental, } \\
\text { restauración del } \\
\text { hábitat }\end{array}$ & $\begin{array}{l}\text { Servicios para } \\
\text { mejorar la vida } \\
\text { de la comunidad }\end{array}$ & & \\
\hline Humanidad & $\begin{array}{c}\text { Acciones } \\
\text { económicas } \\
\text { igualitarias, } \\
\text { internalización } \\
\text { de costes } \\
\text { externos }\end{array}$ & $\begin{array}{c}\text { Estrategias y } \\
\text { prácticas que } \\
\text { beneficien a la } \\
\text { biosfera }\end{array}$ & $\begin{array}{l}\text { Estrategias que } \\
\text { beneficien la } \\
\text { comunidad y la } \\
\text { cultura en todo } \\
\text { el mundo }\end{array}$ & & \\
\hline $\begin{array}{c}\text { Generaciones } \\
\text { Futuras }\end{array}$ & $\begin{array}{l}\text { Inversiones } \\
\text { socialmente } \\
\text { responsables, } \\
\text { fondos } \\
\text { disponibles de } \\
\text { I+D }\end{array}$ & $\begin{array}{l}\text { Minimizar el } \\
\text { impacto medio } \\
\text { ambiental y } \\
\text { restaurar el } \\
\text { hábitat }\end{array}$ & $\begin{array}{l}\text { Cultura, } \\
\text { seguridad y } \\
\text { desarrollo } \\
\text { sostenible }\end{array}$ & & \\
\hline $\begin{array}{l}\text { Mundo } \\
\text { Natural }\end{array}$ & $\begin{array}{l}\text { Devolución de } \\
\text { los Fondos } \\
\text { Invertidos }\end{array}$ & $\begin{array}{l}\text { Prácticas } \\
\text { sostenibles y } \\
\text { diversidad } \\
\text { natural }\end{array}$ & $\begin{array}{c}\text { Trato humano } \\
\text { durante toda la } \\
\text { vida }\end{array}$ & & \\
\hline \multicolumn{6}{|c|}{ Total beneficios obtenidos } \\
\hline \multicolumn{5}{|c|}{ Total de costos incurridos } & \\
\hline \multicolumn{5}{|c|}{ Total beneficios - costos $=$ beneficio sostenible } & \\
\hline
\end{tabular}

Fuente: elaboración, con base en García (2015, pp. 68-69).

\section{Revista Activos}

ISSN: 0124-5805 | e-ISSN: 2500-5278 | DOI: https://doi.org/10.15332/25005278

Vol. 19 N.o 1 | enero-junio de 2021 
Con el tiempo, se han realizado adaptaciones al modelo TCR para medir el desempeño económico, social y ambiental, así como a las directrices de contabilidad sustentable de la GRI por medio de los indicadores (Lamberton, 2005). El modelo TCR no es algo acabado y se tiene que monitorear para actualizarlo de acuerdo con las necesidades del contexto ya que las tres líneas en que se apoya, económica, medioambiental y social, se consideran dinámicas, así como las variantes que se pueden presentar al considerar los códigos de conducta y los valores empresariales que complementaran la TCR (Fauzi et al., 2010).

Finalmente, en calidad de crítica constructiva al TCR este no es un modelo de medición; desde nuestra óptica es un modelo de exhibición del actuar sustentable de la empresa. Se nota la ausencia de indicadores para las diferentes dimensiones y grupos que utiliza el modelo, en calidad de estándares uniformes. Además, para presentar las memorias o informes de sustentabilidad, que emanan de la contabilidad sustentable, es prudente tomar en cuenta lo emitido en normatividad contable.

\section{Normas y pronunciamientos contables relacionados con la sustentabilidad}

Se considera pertinente exponer la inexistencia de criterios, normas o pronunciamientos relacionados con el tema de sustentabilidad dentro de las Normas Internacionales de Contabilidad. La International Accounting Standards Boards (IASB) publica la Norma Internacional (NIC) 36, vigente en 2021, que aborda la medición de las responsabilidades medioambientales y la depreciación de los activos medioambientales; la NIC 37, que versa sobre el reconocimiento de las responsabilidades medioambientales, y la NIC 38, que aborda el inmovilizado material (Silva, y Garrido, 2006). 
Para las pymes la NIIF en un discurso sencillo es la extracción de los conceptos fundamentales del marco conceptual para la preparación y presentación de estados financieros del IASB (2008), por lo que se puede considerar la posibilidad de tomar en cuenta las NIIF para pymes siguientes: sección 27, que se identifica con la NIC 36, que refiere la medición de las responsabilidades medioambientales y la depreciación de los activos medioambientales; sección 21, relacionada con la NIC 37 que versa sobre el reconocimiento de las responsabilidades medioambientales; y sección 18, identificada con la NIC 38 el inmovilizado material.

Lo anteriormente incluido del GRI G4, de la TCR y las normas y pronunciamientos contables relacionados con la sustentabilidad han apoyado a empresas en diversos lugares del mundo para que incursionen en la presentación de memorias también conocidas como informes de sustentabilidad.

\section{Referencias de empresa que elaboran memorias o informes de sostenibilidad}

Para febrero de 2021, según el informe Divulgación ASG y de sostenibilidad en los mercados de capitales: una mirada a América Latina (2020), en el que intervienen GRI Hispanoamérica y AG sustentable, de 762 empresas que cotizan en bolsa, localizadas en Argentina, Chile, Colombia, México y Perú, 286 (que representan el 37.5 \%) elaboran un informe de sostenibilidad. Considerando información por país, el $23 \%$ de las empresas peruanas que cotizan en bolsa realizan informes de sostenibilidad, 34 \% de las empresas chilenas, $36 \%$ de las empresas argentinas, $55 \%$ de las empresas mexicanas y $69 \%$ de las empresas colombianas. Lo anterior permite tener una perspectiva de las empresas que realizan prácticas de sostenibilidad en Latinoamérica (Global Reporting Initiative, 2020). 
En complemento con lo anterior, $87.8 \%$ de las empresas que realizan informes de sostenibilidad se apoya en la Guía del GRI, y algunas otras empresas se apoyan en los lineamientos del Consejo Internacional de Información Integrada (IIRC) y Sustainability Accounting Standards Board (SASB) (Global Reporting Initiative, 2020).

La información anterior deja claro el recurrir a diferentes apoyos para la elaboración de los informes de sustentabilidad y por ello el 14 de octubre 2020, se dio a conocer los cinco referentes que aportan apoyos para elaborar los informes de sostenibilidad: Índice de sustentabilidad (CDP), Climate Disclosure Standards Board (CDSB), Global Reporting Initiative (GRI), International Integrated Reporting Council (IIRC) y Sustainability Accounting Standards Board (SASB), para que en un acuerdo común se considere un modelo único para los informes de sostenibilidad que vincule datos sostenibles con la información financiera (Corresponsables. 2020). Como se mencionó, la participación en los reportes de sostenibilidad y acuerdos para la elaboración de estos se enfocan en las grandes empresas, lo que abre la oportunidad de trabajar la presentación de los reportes de sostenibilidad para las pymes.

\section{Pequeñas y medianas empresas (pymes)}

Con una visión actual, se pueden considerar dos tipos de empresas: las tradicionales, a las que únicamente les preocupa comercializar y producir algún producto o prestar servicios para obtener utilidades. Las empresas modernas, también nombradas competitivas, deben además obtener utilidades, cuidar y preocuparse por el entorno que las rodea y tener posicionamiento en el mercado.

Hoy en día, las empresas se encuentran inmersas en una economía global y deben identificar los impactos desfavorables que le puedan generar al 
medio ambiente, a lo social y por consiguiente poder tener un menoscabo económico.

De acuerdo con Cajiga (2008), la empresa moderna se ocupa de que sus operaciones sean sustentables en lo económico, lo social y lo ambiental; preservar el medio ambiente y la sustentabilidad de las generaciones futuras, y reconocer los intereses de los grupos con los que se relaciona. Es una nueva visión que integra el respeto por las personas, los valores éticos, la comunidad y el medioambiente, sin importar el sector al que pertenece, su tamaño o nacionalidad.

Las pequeñas y medianas empresas (pymes), independientemente de la naturaleza de su actividad principal, de acuerdo con Elmer (1967), presentan las características históricas que identifican a todas las culturas del mundo desde tiempos muy lejanos, prácticamente desde que el hombre se volvió sedentario.

Hoy en día, las empresas deben ser eficientes, competitivas y ofrecer productos y servicios de calidad, y las condiciones del mercado demandan de las empresas mejorar la calidad. Para que puedan lograrlo tienen que fomentar y actualizar las capacidades productivas y administrativas, lo que genera mejores condiciones en las empresas y, a su vez, forja un aumento en la creación de negocios en su entorno.

Las micro-, pequeñas y medianas empresas desempeñan un papel importante en el desarrollo económico. Por ejemplo en México, las estas empresas generan $72 \%$ del empleo y representan el $52 \%$ del producto interno bruto del país (Comisión Nacional para la Protección y Defensa de los Usuarios de Servicios Financieros [Condusef], 2019). Por esto, su presencia es un apoyo importante en economía. 


\section{Metodología}

El trabajo se enfoca en investigar sobre la contabilidad sustentable, para poder conceptualizarla, e identificar sus ventajas, desventajas y los beneficios que tendrían las pymes con su aplicación, en las dimensiones económica, medioambiental y social de la sustentabilidad.

Para el desarrollo del trabajo, se aplicó la investigación documental a través de la recopilación de la información para presentar la conceptualización de los elementos que integran la revisión de la literatura. Se consideró la sustentabilidad, la contabilidad sustentable y los apoyos para la elaboración de las memorias o informes de sustentabilidad, con predominio de un enfoque subjetivo, considerando un estudio exploratorio.

Con base en la revisión de la literatura, se procedió a realizar un cuadro comparativo de indicadores de la Guía GRI G4 con los de TCR, para tener de forma empírica el análisis elementos y realizar una propuesta de presentación de información sustentable en cuatro cuentas de resultados. Se tomó como punto de partida las dimensiones de la sustentabilidad económica, medioambiental y social, y se adicionó la cultura, pues esta toma importancia en las empresas de acuerdo en el contexto en el que se encuentren.

\section{Resultados empíricos}

Los resultados se presentan según el orden marcado en el objetivo: indagar respecto a la contabilidad sustentable, para poder conceptualizarla e identificar sus ventajas, desventajas y los beneficios que tendrían las pymes con su aplicación, en la dimensión económica, ambiental y social de la sustentabilidad, y además la dimensión cultural. 
De forma empírica, se identifica que existe poca información para el tema de contabilidad sustentable, pero se encuentra abundante información concerniente a la contabilidad ambiental, con apoyo en el desarrollo del punto de sustentabilidad. Con base en la escasa literatura encontrada se define a la contabilidad sustentable de la siguiente forma: la contabilidad sustentable presenta en términos cuantitativos las acciones realizadas por la empresa en las distintas dimensiones de la sustentabilidad, apoyando a la empresa para evidenciar el trabajo a favor de la sustentabilidad y toma de decisiones.

Se caracteriza como una contabilidad que contempla las dimensiones de la sustentabilidad y que exhibe las acciones a favor de ella realizadas por la empresa, pero no las mide. Tiene como ventaja mejorar la imagen de la empresa en lo interno y externo con los terceros relacionados y sirve de apoyo a la empresa en la toma de decisiones, de modo que, al evidenciar la empresa sus prácticas sustentables, llegue a ser reconocida como empresa sustentable.

Como desventajas se encontró falta de indicadores o estándares unificados para su aplicación, así como ausencia de metodologías o modelos que apoyen la aplicación de aquella de forma unificada. A continuación se presenta el comparativo de indicadores y análisis de los estos, que sirvió como base ratificar cada dimensión de la sustentabilidad.

\section{Comparativo de indicadores GRI con TCR}

Con base en el contenido de las tablas 1, 2, 3, que incluyen los indicadores del GRI G4, y la tabla 4, que contiene la matriz de indicadores de TCR, se procedió a hacer un análisis comparativo de su contenido:

La primera similitud identificada es en las categorías económica, medio ambiente y desempeño social de la guía GRI G4. Con los grupos de TCR 
economía y finanzas, medio ambiente-ecología y acción social. De esta manera, se empareja la categoría económica con el grupo economía y finanzas, la categoría medio ambiente con el grupo medio ambienteecología y la categoría desempeño social con el grupo acción social.

El GRI G4 incluye 44 aspectos y TRC 10 subgrupos. Los primeros manejan indicadores por categoría y los segundos se abordan en cada grupo. $\mathrm{Al}$ proceder al análisis se identificaron similitudes en que ambos hacen referencia a propietarios, empleados y empleo, clientes, proveedores, mercado, biosfera y comunidad entre otros. Identificadas las similitudes y se notó consistencia entre lo que sugiere la Guía de GRI G4 para los reportes o informes de sustentabilidad con el contenido de TCR.

De forma empírica se procede a presentar la propuesta del reporte de sustentabilidad de cuatro líneas de cuentas de resultados. Específicamente, se identificó en ambas propuestas comparadas y analizadas beneficios económicos netos para propietarios, empleados, clientes, proveedores, mercado y comunidad. En lo referente al medio ambiente se destaca el uso óptimo de recursos, responsabilidad para los deshechos, emisiones riesgos laborales, involucrando a empleados, clientes, proveedores y comunidad. Finalmente, lo concerniente a lo social se aprecia considerar la igualdad, el respeto a los derechos humanos, capacitación y se considera evitar la discriminación, los puntos tomados en cuenta para la comparación y análisis se aprecian en la tabla 5 .

Tabla 5. Puntos considerados para la comparación de las propuestas GRI y TRC

\begin{tabular}{|c|c|c|c|}
\hline Propuesta & Autor & Categorías /grupos & Particularidades \\
\hline Guía GRI G4 & $\begin{array}{c}\text { Global Reporting } \\
\text { Initiative }\end{array}$ & Económica & $\begin{array}{c}\text { Considera en la categoría desempeño } \\
\text { social las subcategorías: }\end{array}$ \\
& Medio ambiente & Prácticas laborales y trabajo digno \\
\hline
\end{tabular}




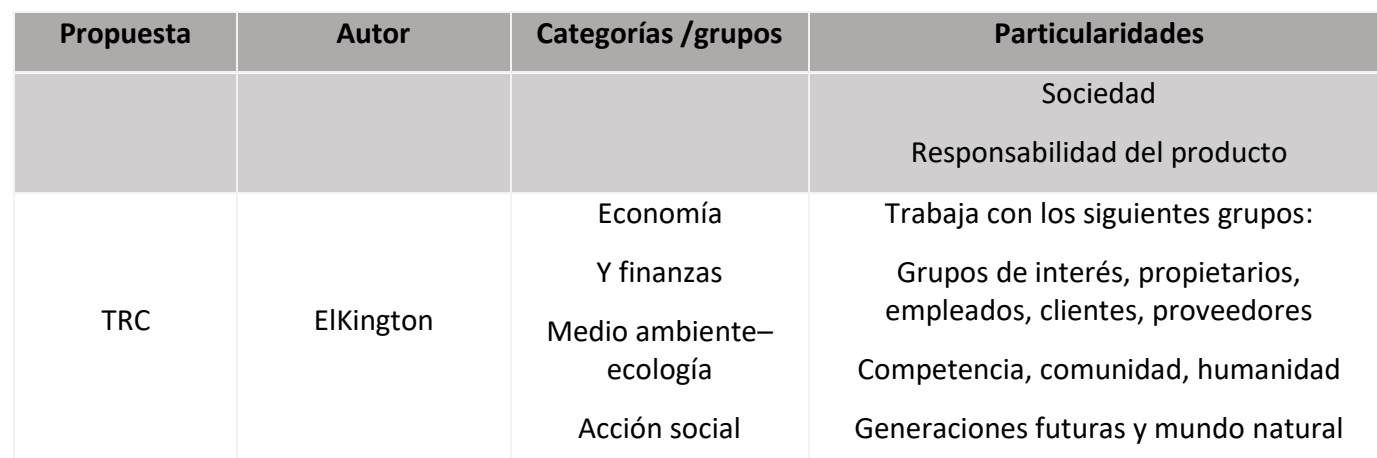

Fuente: García et al. (2010).

\section{Propuesta}

Posteriormente, con base en el análisis anterior de los indicadores del GRI con los de TCR, se procedió a realizar, a partir de García (2015), la propuesta de una matriz para trabajar el modelo TCR, donde se consideran las tres dimensiones clásicas de la sustentabilidad: económica, ambiental y social, y la dimensión Cultura. El modelo de cuatro cuentas de resultados (CCR), que respeta las exigencias de estructura señaladas en las NIF (2021), se muestra en la tabla 6. La dimensión cultura justifica su inclusión, en la importancia que tiene en los diferentes contextos para las personas, situación que se relaciona fuertemente con la dimensión social. Utiliza un lenguaje sencillo y asequible para facilitar el manejo de la matriz propuesta por las pymes. 
Tabla 6. Matriz de apoyo para el modelo CCR

\begin{tabular}{|c|c|c|c|c|c|c|}
\hline \multicolumn{7}{|c|}{$\begin{array}{l}\text { Nombre de la empresa } \\
\text { Reporte de sustentabilidad } \\
\text { Del x de a z de } 202 . \text {. }\end{array}$} \\
\hline Grupo & $\begin{array}{l}\text { Dimensión Economía y } \\
\text { finanzas }\end{array}$ & $\begin{array}{l}\text { Dimensión Medio } \\
\text { ambiente-ecología }\end{array}$ & $\begin{array}{l}\text { Dimensión Acción } \\
\text { social }\end{array}$ & Dimensión Cultura & $\begin{array}{l}\text { Total } \\
\text { Es el resultado de la } \\
\text { suma de los } \\
\text { beneficios totales } \\
\text { obtenidos }\end{array}$ & $\begin{array}{c}\text { Total } \\
\text { Resultado de la } \\
\text { suma de los costos } \\
\text { totales incurridos }\end{array}$ \\
\hline Grupo de Interés & $\begin{array}{l}\text { Incluir los costos del } \\
\text { impacto del desarrollo } \\
\text { económico de la } \\
\text { empresa. }\end{array}$ & $\begin{array}{l}\text { Incluir los costos del } \\
\text { impacto medio } \\
\text { ambiental de la } \\
\text { empresa. }\end{array}$ & $\begin{array}{l}\text { Incluir los costos del } \\
\text { impacto de la } \\
\text { empresa en la } \\
\text { sociedad }\end{array}$ & $\begin{array}{c}\text { Incluir los costos de } \\
\text { Costumbres culturales } \\
\text { de: } \\
\text { Colaboradores } \\
\text { Comunidad cercana a } \\
\text { la empresa. } \\
\text { Costumbres } \\
\text { practicadas en el } \\
\text { entorno de la empresa } \\
\text { y terceros } \\
\text { relacionados. }\end{array}$ & & \\
\hline Propietarios & $\begin{array}{l}\text { Retorno de la inversión. } \\
\text { valor de la acción. }\end{array}$ & $\begin{array}{l}\text { Reducción del riesgo. } \\
\text { Por el uso racional de } \\
\text { los recursos. }\end{array}$ & $\begin{array}{l}\text { Imagen pública. } \\
\text { Prácticas éticas y } \\
\quad \text { legales. }\end{array}$ & $\begin{array}{c}\text { Apoyo para actividades } \\
\text { propias de la cultura de } \\
\text { la comunidad y el } \\
\text { entorno }\end{array}$ & & \\
\hline Empleados & Beneficios sociales & $\begin{array}{c}\text { Niveles de riesgo } \\
\text { laboral }\end{array}$ & $\begin{array}{c}\text { Desarrollo } \\
\text { profesional, } \\
\text { Cultura corporativa }\end{array}$ & $\begin{array}{l}\text { Apoyo para actividades } \\
\text { propias de la cultura } \\
\text { para los grupos de } \\
\text { interés internos }\end{array}$ & & \\
\hline Clientes & Precio y calidad & $\begin{array}{l}\text { Productos o servicios } \\
\text { seguros y respetuosos } \\
\text { con el medio ambiente }\end{array}$ & $\begin{array}{l}\text { Prácticas éticas y } \\
\text { responsabilidad } \\
\text { social }\end{array}$ & $\begin{array}{l}\text { Apoyo para actividades } \\
\text { propias de la cultura } \\
\text { para los grupos de } \\
\text { interés integrados por } \\
\text { terceros relacionados. }\end{array}$ & & \\
\hline
\end{tabular}

Revista Activos

ISSN: 0124-5805 | e-ISSN: 2500-5278 | DOI: https://doi.org/10.15332/25005278

Vol. 19 N. ${ }^{\circ} 1$ | enero-junio de 2021 
Nombre de la empresa

Reporte de sustentabilidad

Del $x$ de a $z$ de 202 .

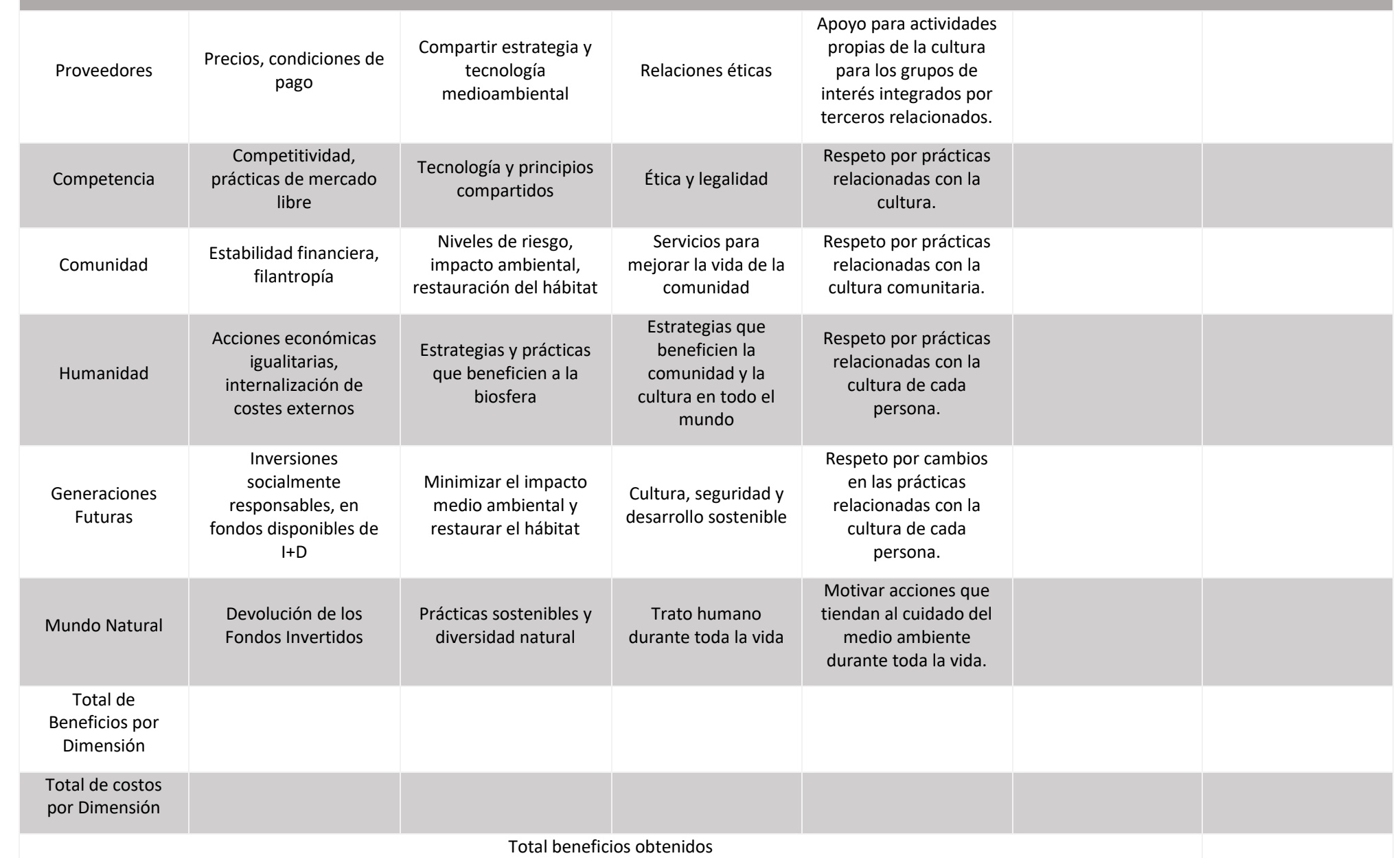

Total beneficios obtenidos

Revista Activos

ISSN: 0124-5805 | e-ISSN: 2500-5278 | DOI: https://doi.org/10.15332/25005278

Vol. 19 N. ${ }^{\circ} 1$ | enero-junio de 2021 
Nombre de la empresa

Reporte de sustentabilidad

Del $x$ de a $z$ de 202.

Total de costos incurridos

Total beneficios - costos $=$ beneficio sostenible

Fuente: elaboración propia con base en García (2015).

Revista Activos

ISSN: 0124-5805 | e-ISSN: 2500-5278 | DOI: https://doi.org/10.15332/25005278

Vol. 19 N.O 1 | enero-junio de 2021 
Las pymes como usuarias de la matriz integrarán en cada espacio según represente un beneficio (ingreso o ahorro) o un costo. Únicamente en los espacios que apliquen según sus prácticas de sustentabilidad correspondientes a un periodo o ejercicio para exhibir los beneficios esperados con su utilización, como tener un reporte cuantitativo que dé cuenta de sus prácticas de sustentabilidad (reciclaje y reutilización de residuos, consumo sustentable, eficiencia energética y ahorro de agua, compras sustentables, etc.) para ser consideradas como pymes sustentables. Esto, además, mejora su imagen, reputación, facilidad de acceso a capital con costos blandos, entre otros (Naiman ,2015; García, 2015, Jiménez, 2015).

\section{Discusión}

La contabilidad sustentable presenta en términos cuantitativos las acciones realizadas por la empresa en las distintas dimensiones de la sustentabilidad, apoyando a la empresa para evidenciar el trabajo a favor de la sustentabilidad y toma de decisiones. Este concepto se propone con base en los trabajos presentados por O'Dwyer y Owen (2005) y Néron (2010).

Se caracteriza a la contabilidad sustentable como una contabilidad que contempla las dimensiones de la sustentabilidad, que exhibe las acciones a favor de la sustentabilidad realizadas por la empresa, pero no las mide; se puede utilizar para exhibir sus prácticas el modelo TCR, en el que no se aprecia limitar su aplicación en las empresas por tamaño o giro. Coincide, en este sentido, con lo señalado por Cintra et al. (2008). El modelo CCR, coincide en su integración con lo abordado por Elkington (1998), Norman y MacDonald (2004); Kleindorfer, Singhal y Van Wassenhove, (2005), e $\operatorname{IMCP}$ (2021). 
Finalmente, se identifica, con la aplicación de la contabilidad sustentable y el reporte generado por ella, la ventaja de mejorar la imagen de la empresa, apoyarla en la toma de decisiones y evidenciar las prácticas sustentables para llegar a ser reconocida como empresa sustentable. Como desventajas, se encontró falta de indicadores o estándares unificados para su aplicación, así como ausencia de metodologías o modelos que apoyen la aplicación de esta concordando con Jiménez (2015).

\section{Conclusiones}

El termino sustentabilidad ha evolucionado en el transcurrir del tiempo y ha adoptado otros nombres como desarrollo sustentable o desarrollo sostenible, con la finalidad de hacerlo más incluyente. Independientemente del nombre con el que se lo denomine, se ha convertido en una exigencia a cumplir por parte de las empresas y organizaciones.

Para que las empresas puedan cumplir con las exigencias sustentables actuales marcadas por la economía globalizada, la sociedad y la competencia entre otros, los organismos internaciones como la UE y ONU comparten propuestas de acciones empresariales que apoyen a la sustentabilidad.

Para hablar de la contabilidad sustentable, hay que realizar un recorrido en el tiempo y mencionar, en primer lugar, la contabilidad financiera. De ella se derivan las contabilidades especializadas, como la contabilidad ambiental, que precede a la contabilidad sustentable. Esta última aplica de manera más amplia considerando las dimensiones de la sustentabilidad y apoya a las empresas a presentar las acciones que realizan a favor de la ya referida sustentabilidad. Para poner en práctica la contabilidad sustentable y se obtengan resultados con criterios homogéneos en las empresas que la utilicen, se debe tener una normatividad de forma general 
o con convergencia, para unificar criterios entre los contadores, además de estándares y un sistema para su aplicación.

Los modelos más conocidos aplicables a la contabilidad sustentable en relación con las memorias o informes sustentables son el TCR, que contempla tres "P" (pickings, people and planet) y los indicadores del GRI G4. Estos se convierten en referentes por si la contabilidad sustentable y pueden llegar a exigirse en un futuro en las empresas para exhibir las acciones empresariales a favor de la sustentabilidad.

La empresa tradicional, si quiere mantenerse activa y competitiva en el mercado, debe realizar un cambio en su forma de negocios y considerar lo económico, lo social, lo ambiental y lo cultural para transformarse en una empresa sustentable.

En este primer trabajo sobre contabilidad sustentable, de forma empírica se considera haber alcanzado el objetivo fijado: indagar respecto a la contabilidad sustentable, para poder conceptualizarla, caracterizarla, identificar sus ventajas, desventajas y los beneficios que tendrían las pymes con su aplicación, en la dimensión económica, ambiental y social de la sustentabilidad cerrando con la presentación de la propuesta CCR.

\section{Referencias}

Cajiga. J. (2008). El Concepto de responsabilidad social Empresarial. Centro Mexicano para la Filantropía.

https://www.cemefi.org/esr/images/stories/pdf/esr/concepto_esr.pdf.

Comisión Nacional para la Protección y Defensa de los Usuarios de Servicios Financieros. (2019). Pymes. https://www.condusef.gob.mx/Revista/index.php/usuariointeligente/educacion-financiera/492-pymes. 
Corresponsables. (2020, 14 de octubre). ODS16. Nace un nuevo modelo estándar de reporting corporativo para integrar la contabilidad financiera y de sostenibilidad. https://www.correspponsables.com/actualidad/ods16modeloestandar-reporting corporativo-contabilidadfinanciera-sustentabilidad-cdpcdsb-gri-iirc-sasb

Curvelo, J. (2011). La epistemología como campo de posibilidad para el desarrollo científico de la contabilidad. En A. Cano, Desarrollo Científico de la contabilidad. Universidad de Medellín.

Deniz, J. (2007). La regulación de la información contable medioambiental en España. La Resolución del Instituto de Contabilidad y Auditoría de Cuentas del 25 de marzo de 2002. Contaduría y Administración, 8(221), 164-192.

Elkington. J. (1998). Cannibals with forks: The triple bottom line of 21st century business. New Society Publishers.

Elmer, H. (1967). Historia de la economía del mundo occidental. UTEHA.

Etecé. (2020). Ambiente. En Enciclopedia Concepto. Actualizado el 7 de agosto de 2020. https://concepto.de/ambiente-2/\#ixzz6xnSpsuxd

Fauzi, H., Svensson, G. y Rahman, A. (2010). Triple Bottom Line as Sustainable Corporate Performance: A Proposition for the Future. Sustainability, 2, 1345-1360. https://ssrn.com/abstract $=1492934$

Fernández, L. y Carrara, C. N. (2009). Enfoque socioambiental en la formación del contador público. Visión de Futuro, 12(2). https://dialnet.unirioja.es/servlet/articulo? codigo $=5265984$

Gaffikin, M. (2006). The Critique of Accounting Theory. Accounting \& Finance Working Paper. School of Accounting \& Finance, University of Wollongong, 6(25).

García D. y Menegaz A. (2013). Las dimensiones del desarrollo sustentable. En B. Carpinetti (coord.), Introducción al desarrollo sustentable (2. ${ }^{\mathrm{a}}$ ed., pp. 85-145). Universidad Nacional Arturo Jauretche.

García de la Torre, C., Portales, L., Camacho, R. y Arandia, O. (2019). Instrumento de evaluación de sustentabilidad y responsabilidad social en pymes. Administración y Organizaciones, 12(24), 91-103. 
García, M. (2015). La cuenta del triple resultado o triple bottom line. Revista de Contabilidad y Dirección, (20), 65-77.

Garcia, S., Cintra Y., Sousa M. y Rubier, B. (2015). Calidad de la divulgación socio ambiental: un estudio sobre la precisión de las informaciones contables en los informes de sostenibilidad Revista Contemporánea de Contabilidad, 12(25), p. 6794. http://dx.doi.org/10.5007/2175-8069.2015v12n25p95

Global Reporting Initiative (2002). Sustainability Reporting Guidelines. https://www.r3o.org/wp-content/uploads/2020/03/GRIguidelines.pdf

Global Reporting Initiative. (2013). G4 Guía para elaboración de memorias de sostenibilidad. http://www.mas-business.com/docs/Spanish-G4.pdf

Global Reporting Initiative. (2020). Divulgación ASG y de sostenibilidad en los mercados de capitales: una mirada a américa latina.

https://agsustentable.com/novedades/divulgacion-asg-y-de-sostnibilidad-en-losmercaados-de-capitales-una-mirada-a-latam.

Gómez y Ospina, (2005). El informe de sostenibilidad del Global Reporting Initiative (Iniciativa Mundial para la Elaboración de Informes): una contribución fundamental hacia la transparencia con las partes interesadas (stakeholders). Economía, Gestión y Desarrollo, (3), 273-298.

Gray, R. (1992). Accounting and environmentalism: An exploration of the challenge of gently accounting for accountability, transparency, and sustainability. Accounting, Organisations and Society, 17(5), 399-425.

Gray, R., Owen, D. L. y Adams, C. A. (1996). Accounting and Accountability: Changes and Challenges in Corporate Social and Environmental Reporting. Prentice Hall.

Guijt, I. y Mosissev, A. (2001). Herramientas para la evaluación de la sostenibilidad. Parte A: visión general. Unión Mundial para la Naturaleza. https://www.uv.mx/mie/files/2012/10/SESION-8-1-Ev-Sostenibilidadresumen.pdf

Hurtado de Mendoza. (2012). Las Dimensiones de la Sustentabilidad. Dimensiones. https://www.maestriaendocencia.com/lasdimensionesdelasustentabilidad.pdf

Instituto Mexicano de Contadores Públicos. (2021). Normas de información Financiera. Instituto Mexicano de Contadores Públicos. 
Instituto Nacional de Ecología y Cambio Climático. (2018). Presentación de los resultados del inventario nacional de emisiones de gases y compuestos de efecto invernadero. https://www.gob.mx/inecc/prensa/presentacion-de-los-resultadosdel-inventario-nacional-de-emisiones-de-gases-y-compuestos-de-efectoinvernadero.

International Accounting Standard Board. (2008). IFRS - International Accounting Standards Board. https://www.ifrs.org/groups/international-accountingstandards-board/

International Accounting Standard Board. (2021). About the International Accounting Standards Board (Board). https://www.ifrs.org/groups/international-accountingstandards-board/\#about

Jiménez, E. (2013). La contaduría y el desarrollo sustentable [entrada de blog]. Intelecto Mañanero. https://intelectomananero.wordpress.com/la-contaduria-y-eldesarrollo-sustentable/

Jiménez. J. (2015, 7-9 de octubre). La contaduría y el desarrollo sustentable. Cómo mide la contabilidad sustentable. La dimensión social y la importancia del Empleo dentro de ésta [ponencia]. XX Congreso Internacional de Contaduría, Administración e Informática, Universidad Nacional Autónoma de México.

Kain, J. H. (2003). Sociotechnical knowledge: An operationalized approach to localized infrastructure planning and sustainable urban development [tesis doctoral, Chlamers Univertity of Technology]. Researchgate. https://bit.ly/3sn48Nc

Kleindorfer. P., Singhal. K. y Van Wassenhove. L. (2005). Sustainable operations management. Production and Operations Management. V. 14 No. 4. pp 482-492.

Lamberton, G. (2005). Sustainability accounting: A brief history and conceptual framework. Accounting Forum, 29(1), 7-26. http://dx.doi.org/10.1016/j.accfor.2004.11.001

Lezama, J. L. y Domínguez, J. (2006). Medio ambiente y sustentabilidad urbana. Papeles de población, 12(49), 153-176.

Mejía, E. y Ceballos, O. (2016). Medición contable de la sustentabilidad organizacional desde la Teoría Tridimensional de la Contabilidad. Revista Científica General José María Córdova, 14(18), 215-243.

Revista Activos

ISSN: 0124-5805 | e-ISSN: 2500-5278 | DOI: https://doi.org/10.15332/25005278

Vol. 19 N.o 1 | enero-junio de 2021 
Ministerio de Medio Ambiente de España. (1999). Libro blanco de la educación ambiental en España en pocas palabras. Ministerio de Medio Ambiente; Secretaría General de Medio Ambiente. https://www.miteco.gob.es/es/ceneam/recursos/documentos/pocas tcm3077432.pdf

Naiman, P. (2015). Sustentabilidad, replanteando el lugar de nuestra empresa en la sociedad. Tandem. Soluciones de decisión. http://tandemsd.com/sustentabilidadreplanteando-el-lugar-de-nuestra-empresa-en-la-sociedad/

Néron. P. (2010). Business and the polis: What does it mean to see corporations as political actors? Journal of Business Ethics, 94, 333-352.

https://doi.org/10.1007/s10551-009-0266-y

Norman, W. y MacDonald. C. (2004). Getting to the Bottom of Triple Bottom Line Business Ethics Quarterly, 14(2). https://econpapers.repec.org/article/cupbuetqu/v_3a14_3ay_3a2004_3ai_3ao2 3ap 3a24.3-262 5 foo.htm

O’Dwyer, B. y Owen, D. (2005). Assurance statement practice in environmental, social and sustainability reporting: a critical evaluation. The British Accounting Review, 37(2), 205-229. https://doi.org/10.1016/j.bar.2005.01.005

Organización de las Naciones Unidas. (1987). Informe de Brundtland. Informe de la Comisión Mundial Sobre el medio ambiente y el Desarrollo [A/42/427]. http://www.ecominga.uqam.ca/PDF/BIBLIOGRAPHIE/GUIDE_LECTURE_1/C MMAD-Informe-Comision-Brundtland-sobre-Medio-Ambiente-Desarrollo.pdf

Ramírez, P. y Arenas, V. (2007). La acción empresarial para el desarrollo sostenible: clarificando algunos conceptos. Documentación Social, 146, 43-62.

Secretaría de Medio Ambiente y Recursos Naturales. (2018). Diferencia entre sustentable y sostenible. Página oficial del Gobierno de México [entrada de blog]. https://www.gob.mx/semarnat/articulos/diferencia-entre-sustentable-ysostenible

Serageldin I. y Steer A. (1994). Epilogue: Expanding the Capital Stock. En Making Development Sustainable (n. ${ }^{\circ}$, pp. 30-33). ESD. 
Silva, B. y Garrido, C. (2006). La convergencia a las Normas Internacionales de Información Financiera en Chile. Capiv Review. (4), 9-19. https://dialnet.unirioja.es/descarga/articulo/2573345.pdf

Spangenberg, J. y Bonniot, O. (1998). Sustainability indicators. A Compass on the Road Towards Sustainability (documento 81). Instituto Wuppertal. https://epub.wupperinst.org/frontdoor/deliver/index/docId/721/file/WP81.pdf

Thomson, I. y Bebbington, J. (2005). Social and environmental reporting in the UK: a pedagogic evaluation. Critical Perspectives on Accounting, 16(5), 507-533. https://doi.org/10.1016/j.cpa.2003.06.003

Valentin, A. y Spangenberg, J. H. (2000). A guide to community sustainability indicators. Environmental Impact Assessment Review, 20(3), 381-392. https://doi.org/10.1016/S0195-9255(00)00049-4

Vega, I. y Ricárdez, J. (2017). La contabilidad ecológica: un reto para la evolución de las empresas socialmente responsables en México. En M. González-Valdés (ed.), Retos de las ciencias administrativas desde las economías emergentes: evolución de sociedades (cap. 18) [libro digital]. Instituto Tecnológico y de Estudios Superiores de Monterrey.

Vega, I. y Ricárdez, J. D. (2011, 5-7 de octubre). La contabilidad verde como elemento fundamental dentro de las empresas mexicanas socialmente responsables [ponencia]. XVI Congreso Internacional de Contaduría, Administración e Informática, Universidad Nacional Autónoma de México, México D. F. http://congreso.investiga.fca.unam.mx/docs/xvi/docs/6D.pdf 